\title{
Comparison of past and future simulations of ENSO in CMIP5/PMIP3 and CMIP6/PMIP4 models
}

Josephine R. Brown ${ }^{1}$, Chris M. Brierley ${ }^{2}$, Soon-Il An ${ }^{3}$, Maria-Vittoria Guarino ${ }^{4}$, Samantha Stevenson ${ }^{5}$, Charles J. R. Williams ${ }^{6,7}$, Qiong Zhang ${ }^{8}$, Anni Zhao ${ }^{2}$, Ayako Abe-Ouchi ${ }^{9}$, Pascale Braconnot ${ }^{10}$, Esther C. Brady ${ }^{11}$, Deepak Chandan ${ }^{12}$, Roberta D'Agostino ${ }^{13}$, Chuncheng Guo ${ }^{14}$, Allegra N. LeGrande ${ }^{15}$, Gerrit Lohmann ${ }^{16}$, Polina A. Morozovaa ${ }^{17}$, Rumi Ohgaito ${ }^{18}$, Ryouta O'ishi ${ }^{9}$, Bette L. Otto-Bliesner ${ }^{11}$, W. Richard Peltier ${ }^{12}$, Xiaoxu Shi ${ }^{16}$, Louise Sime $^{4}$, Evgeny M. Volodin ${ }^{19}$, Zhongshi Zhang ${ }^{4,20}$, and Weipeng Zheng ${ }^{21}$

${ }^{1}$ School of Earth Sciences, University of Melbourne, Parkville, VIC, Australia

${ }^{2}$ Department of Geography, University College London, London, UK

${ }^{3}$ Department of Atmospheric Sciences, Yonsei University, Seoul, South Korea

${ }^{4}$ British Antarctic Survey, High Cross, Madingley Road, Cambridge, UK

${ }^{5}$ Bren School of Environmental Sciences and Management, University of California, Santa Barbara, CA, USA

${ }^{6}$ School of Geographical Sciences, University of Bristol, University Road, Bristol, UK

${ }^{7}$ Department of Meteorology, University of Reading, Earley Gate, P.O. Box 243, Reading, UK

${ }^{8}$ Department of Physical Geography and Bolin Centre for Climate Research,

Stockholm University, Stockholm, Sweden

${ }^{9}$ Atmosphere and Ocean Research Institute, University of Tokyo, Kashiwa, Japan

${ }^{10}$ Laboratoire des Sciences du Climat et de l'Environnement-IPSL, unite mixte CEA-CNRS-UVSQ,

Université Paris-Saclay, Gif-sur-Yvette, France

${ }^{11}$ National Center for Atmospheric Research, 1850 Table Mesa Drive, Boulder, CO, USA

${ }^{12}$ Department of Physics, University of Toronto, 60 St. George Street, Toronto, Ontario, Canada

${ }^{13}$ Max-Planck-Institut für Meteorologie, Bundesstrasse 53, Hamburg, Germany

${ }^{14}$ NORCE Norwegian Research Centre, Bjerknes Centre for Climate Research, Bergen, Norway

${ }^{15}$ NASA Goddard Institute for Space Studies, 2880 Broadway, New York, NY, USA

${ }^{16}$ Alfred Wegener Institute Helmholtz Centre for Polar and Marine Research Bussestr. 24, Bremerhaven, Germany

${ }^{17}$ Institute of Geography Russian Academy of Sciences, Staromonetny L. 29, Moscow, Russia

${ }^{18}$ Japan Agency for Marine-Earth Science and Technology, 3173-25 Showamachi,

Kanazawa-ward, Yokohama, Japan

${ }^{19}$ Marchuk Institute of Numerical Mathematics of the Russian Academy of Sciences, Moscow, Russia

${ }^{20}$ Department of Atmospheric Science, School of Environmental studies, China University of Geoscience, Wuhan, China

${ }^{21}$ State Key Laboratory of Numerical Modeling for Atmospheric Sciences and Geophysical Fluid Dynamics, Institute of Atmospheric Physics, Chinese Academy of Sciences, Beijing, China

Correspondence: Josephine R. Brown (josephine.brown@unimelb.edu.au)

Received: 19 December 2019 - Discussion started: 4 February 2020

Revised: 16 July 2020 - Accepted: 27 July 2020 - Published: 28 September 2020 
Abstract. El Niño-Southern Oscillation (ENSO) is the strongest mode of interannual climate variability in the current climate, influencing ecosystems, agriculture, and weather systems across the globe, but future projections of ENSO frequency and amplitude remain highly uncertain. A comparison of changes in ENSO in a range of past and future climate simulations can provide insights into the sensitivity of ENSO to changes in the mean state, including changes in the seasonality of incoming solar radiation, global average temperatures, and spatial patterns of sea surface temperatures. As a comprehensive set of coupled model simulations is now available for both palaeoclimate time slices (the Last Glacial Maximum, mid-Holocene, and last interglacial) and idealised future warming scenarios $\left(1 \%\right.$ per year $\mathrm{CO}_{2}$ increase, abrupt four-time $\mathrm{CO}_{2}$ increase), this allows a detailed evaluation of ENSO changes in this wide range of climates. Such a comparison can assist in constraining uncertainty in future projections, providing insights into model agreement and the sensitivity of ENSO to a range of factors. The majority of models simulate a consistent weakening of ENSO activity in the last interglacial and mid-Holocene experiments, and there is an ensemble mean reduction of variability in the western equatorial Pacific in the Last Glacial Maximum experiments. Changes in global temperature produce a weaker precipitation response to ENSO in the cold Last Glacial Maximum experiments and an enhanced precipitation response to ENSO in the warm increased $\mathrm{CO}_{2}$ experiments. No consistent relationship between changes in ENSO amplitude and annual cycle was identified across experiments.

\section{Introduction}

When the first El Niño-Southern Oscillation (ENSO) event occurred in Earth's history is unclear. However, in light of air-sea coupled feedbacks, the birth of ENSO must be strongly related to the emergence of the tropical eastern Pacific cold tongue and its zonal sea surface temperature (SST) contrast with the tropical western Pacific warm pool. It has been proposed that the gradual uplifting of the Central American continent starting from around 24 million years BP (before present) (hereafter Ma) triggered the development of the Pacific cold tongue by reducing the surface water exchange between oceans (e.g. Chaisson and Ravelo, 2000). Palaeoproxies revealed that the Pliocene warm period ( 4.5-3.0 Ma) recorded a very weak zonal SST contrast, sometimes referred to as a "permanent El Niño-like state" (Brierley et al., 2009; Fedorov et al., 2013, 2006; Ravelo et al., 2006; White and Ravelo, 2020). Despite the weak mean east-west SST gradient, some proxy records (Scroxton et al., 2011; Watanabe et al., 2011) and general circulation model (GCM) experiments (Burls and Fedorov, 2014; Haywood et al., 2007) suggest the existence of interannual ENSO variability during the mid-Pliocene, at least sporadically. During the last interglacial (approximately 116-129 thousand years BP, hereafter ka), orbital changes appear to have influenced the strength of ENSO variability, with coral proxy records providing evidence for relatively weak ENSO amplitude (Hughen et al., 1999; Tudhope et al., 2001). Model studies have also simulated reduced ENSO variability during the last interglacial (An et al., 2017; Kukla et al., 2002; Salau et al., 2012).

Ice sheet dynamics have also been thought to influence the behaviour of ENSO (Liu et al., 2014). Large-scale ice sheets in the Northern Hemisphere expanded from 2.7 Ma onwards (Jansen et al., 2000). Global climate subsequently underwent a series of glacial-interglacial cycles, with the most recent glacial period reaching maximum levels of global cooling and lower sea levels around $21-18 \mathrm{ka}$, the so-called "Last Glacial Maximum" (LGM). The tropical climate state during the LGM was $1-3{ }^{\circ} \mathrm{C}$ colder on average than the present day. Reconstructions of LGM ENSO activity are uncertain, with some studies finding increased ENSO variability (Koutavas and Joanides, 2012; Sadekov et al., 2013) and others finding reduced ENSO variability (Leduc et al., 2009). A recent synthesis of evidence from planktonic foraminifera (Ford et al., 2015, 2018) supports reduced ENSO variability but increased seasonality and a deepened equatorial Pacific thermocline during the LGM. Model simulations using an isotope-enabled GCM (Zhu et al., 2017) further assist in reconciling the proxy records, as the model simulates a $30 \%$ weakening of ENSO during the LGM but an increased annual cycle contributing to enhanced variability in the foraminifera records of Koutavas and Joanides (2012). Coupled climate models included in the second and third phases of the Paleoclimate Modelling Intercomparison Project (PMIP2 and PMIP3, respectively) simulate a wide range of ENSO changes for the LGM (Masson-Delmotte et al., 2014; Saint-Lu et al., 2015; Zheng et al., 2008).

A number of proxy records provide evidence for weakened ENSO variability during the mid-Holocene (around $6 \mathrm{ka}$ ), although the timing of this weakening varies between records (e.g. Carré et al., 2014; Conroy et al., 2008; Donders et al., 2005; Koutavas and Joanides, 2012; Koutavas et al., 2006; McGregor and Gagan, 2004; McGregor et al., 2013; Rein et al., 2005; Riedinger et al., 2002; Tudhope et al., 2001; White et al., 2018). Cobb et al. (2013) argued that coral records from the central Pacific do not show a statistically significant reduction in mid-Holocene ENSO variability but a new ensemble of central Pacific records (Grothe et al., 2019) provides evidence for a significant reduction from 3 to $5 \mathrm{ka}$. Some studies have suggested that disagreement between the magnitude of mid-Holocene ENSO reduction in different proxy records may be due to shifts in the spatial pattern of ENSO variability between the eastern and central Pacific (e.g. Carré et al., 2014; Karamperidou et al., 2015). A synthesis of Holocene ENSO proxy records (Emile-Geay et al., 2016) identifies a sustained reduction in ENSO variability from 3 to $5 \mathrm{ka}$, with a reduction of $64 \%$ in the central 
Pacific. During the earlier "mid-Holocene" period from 5.5 to $7.5 \mathrm{ka}$, reduced ENSO variance occurs in the central, western, and eastern Pacific (66\%, 50\%, and 33\%, respectively) with larger uncertainty ranges (Emile-Geay et al., 2016).

Climate models generally simulate reduced mid-Holocene ENSO activity. For example, transient simulations for part of or the whole Holocene period using an intermediate oceanatmosphere coupled model of the tropical Pacific climate forced by the orbital forcing (Clement et al., 2000), a fully coupled general circulation model with the time-varying climate forcing including orbital, greenhouse gas, meltwater flux, and continental ice sheets (Liu et al., 2014), and a hybrid-type simulation using a combination of the intermediate complexity of Earth-system-model-forced orbital forcing and intermediate coupled tropical Pacific climate model with varying background state (An et al., 2018) all showed a significant reduction of ENSO intensity during mid-Holocene and its recovery to modern-day ENSO strength around the late Holocene. A study with another set of transient Holocene simulations with coupled climate models confirmed this result but found that it was the result of chaotic processes (Braconnot et al., 2019).

The mid-Holocene time-slice simulations of PMIP2 and PMIP3, all of which fixed climate forcing at $6 \mathrm{ka}$, also showed suppressed ENSO variability in most of the models compared to the pre-industrial perpetual simulations (Braconnot et al., 2007; Chen et al., 2019b; Chiang et al., 2009; Zheng et al., 2008). The reduction of interannual variability in PMIP models was especially dominant over the equatorial central Pacific (An and Bong, 2018; Chen et al., 2019b). However, the reduction of ENSO intensity in the $6 \mathrm{ka}$ run of PMIP3 compared to the $0 \mathrm{ka}$ run $(\sim 5 \%$ reduction in the standard deviation of NINO3.4 index from 11 models), in which more state-of-the-art GCMs participated, was rather weaker than that in PMIP2 $(\sim 18 \%$ reduction in the standard deviation of NINO3.4 index from six models) (An and Choi, 2014; Masson-Delmotte et al., 2014). A comprehensive model-data comparison (Emile-Geay et al., 2016) found that models underestimated the reduction in mid-Holocene ENSO variability compared with proxy records, and also simulated an inverse relationship between the amplitude of the seasonal cycle and ENSO variability which was not evident in proxy reconstructions.

Over the last millennium, ENSO has exhibited considerable natural variability (Cobb et al., 2003). Multi-proxy reconstructions of central tropical Pacific SST confirm that vigorous decadal to multi-decadal variability of ENSO occurred (Emile-Geay et al., 2013), while eastern Pacific ocean sediment records suggest a mid-millennium shift from damped to amplified ENSO variability (Rustic et al., 2015). However, as for all the palaeoclimate intervals considered, the assessment of ENSO variability over the last millennium is rather uncertain due to the temporal and spatial sparseness of palaeoENSO proxy records (Cobb et al., 2003, 2013; Khider et al., 2011). Last-millennium experiments from PMIP3 mod- els showed that ENSO behaviour may be strongly modulated on decadal to centennial timescales over the last millennium, and that teleconnections between ENSO and tropical Pacific climate vary on these timescales (Brown et al., 2016; Lewis and LeGrande, 2015).

The instrumental records of ENSO for the 20th century clearly document the variety of ENSO behaviour, including both temporal and spatial complexity (Timmermann et al., 2018). ENSO complexity includes its seasonal phase locking (Neelin et al., 2000; Stein et al., 2011), the interaction with other timescale climate variability (Eisenman et al., 2005; Levine et al., 2016; Tang and Yu, 2008; Zhang and Gottschalck, 2002), El Niño-La Niña asymmetry in amplitude, duration, and transition (An and Jin, 2004; An and Kim, 2018, 2017; Im et al., 2015; Okumura et al., 2011), the diversity in the peak location (i.e. central and eastern Pacifictype El Niño; (Capotondi et al., 2015), and the combination modes due to interaction between annual and interannual spectra (Stuecker et al., 2015; Timmermann et al., 2018). Interestingly, the dominant tendency of eastern Pacific-type El Niño occurrence during 20th century was replaced by the central Pacific-type El Niño in recent decades (Ashok et al., 2007; Yeh et al., 2014, 2009), and all extreme El Niño events (1982-1983, 1997-1998, and 2015-2016) recorded by the modern instruments occurred around/after the late 20th century. The increased frequency of central Pacific-type events in recent decades is unusual in the context of a palaeo record for the last 400 years (Freund et al., 2019). Such distinct changes in ENSO characteristics through the 20th and 21st centuries may be related to low-frequency modulation by natural variability or the global warming trend due to increasing greenhouse gas concentrations, or a combination of natural and anthropogenic factors (e.g. An et al., 2008; Cai et al., 2015a; Collins, 2000; Gergis and Fowler, 2009; Timmermann et al., 1999; Trenberth and Hoar, 1997; Yang et al., 2018; Yeh et al., 2014; Yeh and Kirtman, 2007).

Although it is still a topic of ongoing debate as to whether the future tropical Pacific climate state becomes "El Niñolike" or "La Niña-like" (referring only to the change in zonal SST gradient) in response to greenhouse warming (An et al., 2012; Cane et al., 1997; Collins et al., 2010; Lian et al., 2018; Seager et al., 2019), recent multi-model studies of projected changes in ENSO under global warming suggested no significant change in terms of mean ENSO amplitude compared to the historical ENSO amplitude (An and Choi, 2015; An et al., 2008; Chen et al., 2017; Christensen et al., 2014; Latif and Keenlyside, 2009; Stevenson, 2012). However, studies have identified robust increases in the extreme hydrological changes associated with El Niño (Cai et al., 2014, 2015a) and La Niña (Cai et al., 2015b), and changes in ENSO-driven precipitation variability (Power et al., 2013). Moreover, even if the global mean temperature is constrained to the limit of $1.5^{\circ} \mathrm{C}$ above pre-industrial levels following the Paris Agreement, a doubling of the frequency of extreme El Niño events may occur (Wang et al., 2017). 
In this paper, we assess ENSO change through time as simulated in the new generation of coupled atmosphereocean climate models for both past and future climates (see Sect. 2.2). We also compare these new simulations with previous generations of climate models. Detailed comparison of the past climate simulations with proxy records is beyond the scope of the current study, and will be the focus of subsequent research. We consider the change in ENSO amplitude, and its dynamical relationship with the change in the mean climate state under past and future conditions spanning colder past climates (Last Glacial Maximum), past climates with an altered seasonal cycle (last interglacial and mid-Holocene), and idealised warming projections (abrupt four-time $\mathrm{CO}_{2}$ and $1 \%$ per year $\mathrm{CO}_{2}$ ) to provide a context for evaluating projections of ENSO change. The methods, models, and experiments are introduced in Sect. 2. Model evaluation is provided in Sect. 3. In Sect. 4, the mean state changes in each experiment relative to the pre-industrial control are described. ENSO amplitude changes are presented in Sect. 5, and changes to ENSO teleconnections are considered in Sect. 6. In Sect. 7, the proposed mechanisms for the ENSO change through time are briefly discussed, and conclusions are given in Sect. 8.

\section{Methods}

This research analyses a total of 140 simulations, across 7 different experiments and 32 climate models. The description of individual simulations is therefore kept brief, and often only the ensemble mean response will be shown. The combined model ensemble will be described in Sect. 2.1, whilst an overview of the experimental designs is provided in Sect. 2.2. The common analysis procedure is outlined in Sect. 2.3.

\subsection{Models}

State-of-the-art coupled global climate models solve the physical equations of the atmosphere and ocean. They are some of the most sophisticated of numerical models and have been constantly developed for several decades. Globally, there are around 40 such models with varying degrees of independence (Knutti et al., 2013). Given the resources required to undertake a single GCM simulation, the international community has settled upon a series of coordinated experiments to facilitate model to model "intercomparison". These are organised under the umbrella of the Coupled Model Intercomparison Project (CMIP). Here, we evaluate and analyse simulations from both the previous phase (phase 5) (CMIP5; Taylor et al., 2012), as well as early results from the current phase (phase 6) (CMIP6; Eyring et al., 2016a). Simulations of past climate are included from the PMIP, which is part of CMIP. Some of the simulations were carried out as part of PMIP phase 3 (PMIP3; Braconnot et al., 2012) and other simulations are part of PMIP phase 4 (PMIP4; Kageyama et al., 2018).

This study provides an opportunity to compare the simulation of ENSO in past and future climates in CMIP5 and CMIP6 generations of models. The simulation of ENSO may be improved in the CMIP6 ensemble relative to the CMIP5 models due to some improvements in the simulation of the mean state, such as a reduced "double ITCZ bias" in tropical Pacific precipitation (Tian and Dong, 2020) and a reduced "cold tongue bias" in equatorial Pacific SSTs (Grose et al., 2020), as shown in Figs. S1 and S2 in the Supplement. Some CMIP6 models also include a more sophisticated treatment of aerosols, higher spatial resolution, and updated parameterisation of process such as convection compared with CMIP5 models.

For inclusion in this study, a model must have both completed at least one palaeoclimate simulation and provided the required output fields for at least 30 years for both this simulation and the pre-industrial control (see Sect. 2.3 for details). The resulting 32 models are listed in Table 1; combined, they contain over 35000 years of monthly ENSO information. Further information about the CMIP5 models is provided in Table 9.A.1 of Flato et al. (2014). The CMIP6 models used in this study are described in more detail in the Supplement and also online on the PMIP4 website https://pmip4.lsce.ipsl.fr/doku.php/database:participants (last access: 8 July 2020).

\subsection{Simulations}

This study uses simulations consisting of seven different experiments. Four of the experiments are part of the CMIP effort and form part of the "DECK" set of core simulations (Eyring et al., 2016a): the pre-industrial and historical and two idealised future warming scenarios. The study also includes three past climate experiments from the PMIP database; the mid-Holocene and Last Glacial Maximum were included in both PMIP3/CMIP5 and PMIP4/CMIP6, whereas the last interglacial was only included in PMIP4/CMIP6.

The mean state and ENSO variability of the models are evaluated in simulations with prescribed historical forcings, known as historical simulations (Hoesly et al., 2018; Meinshausen et al., 2017; van Marle et al., 2017). The specification of the historical simulation differs slightly between CMIP5 and CMIP6, most notably by the CMIP6 simulations being extended until $2015 \mathrm{CE}$. This has minimal influence over the chosen climatological period of 1971-2000. The baseline simulation relative to which all climate changes are calculated is the pre-industrial control (piControl; Eyring et al., 2016a; Stouffer et al., 2004). The piControl simulations represent constant 1850 forcing conditions and have all reached a quasi-stable equilibrium.

The two idealised warming scenarios (abrupt $4 x \mathrm{CO} 2$ and lpctCO2) in the CMIP DECK both involve increases in car- 
Table 1. List of models included in the study and length of simulations based on the number of years of data available for NINO3.4 in the CVDP archive. Additional information about CMIP6/PMIP4 models (indicated in bold) is provided in the Supplement.

\begin{tabular}{lrrrrrrrr}
\hline Model & CMIP gen. & piControl & historical & midHolocene & lgm & lig127k & lpctCO2 & abrupt4xCO2 \\
\hline AWI-ESM-1-1-LR & CMIP6 & 100 & - & 100 & 100 & 100 & - & - \\
BCC-CSM1-1 & CMIP5 & 500 & 163 & 100 & - & - & 140 & 150 \\
CCSM4 & CMIP5 & 1051 & 156 & 301 & 101 & - & 156 & 151 \\
CESM2 & CMIP6 & 1200 & 165 & 700 & - & 700 & 150 & 150 \\
CNRM-CM5 & CMIP5 & 850 & 156 & 200 & 200 & - & 140 & 150 \\
CNRM-CM6-1 & CMIP6 & 500 & 165 & - & - & 301 & 150 & 150 \\
COSMOS-ASO & CMIP5 & 400 & - & - & 600 & - & - & - \\
CSIRO-Mk3-6-0 & CMIP5 & 500 & 156 & 100 & - & - & 140 & 150 \\
CSIRO-Mk3L-1-2 & CMIP5 & 1000 & 150 & 500 & - & - & 140 & - \\
EC-EARTH-3-LR & CMIP6 & 201 & - & 201 & - & - & - & - \\
FGOALS-f3-L & CMIP6 & 561 & 165 & 500 & - & 500 & 160 & 160 \\
FGOALS-g2 & CMIP5 & 700 & 115 & 680 & 100 & - & 244 & 258 \\
FGOALS-g3 & CMIP6 & 700 & - & 500 & - & 500 & - & - \\
FGOALS-s2 & CMIP5 & 501 & - & 100 & - & - & 140 & 150 \\
GISS-E2-1-G & CMIP6 & 851 & 165 & 100 & - & 100 & 51 & 151 \\
GISS-E2-R & CMIP5 & 500 & 156 & 100 & 100 & - & 151 & 151 \\
HadGEM2-CC & CMIP5 & 240 & 145 & 35 & - & - & - & - \\
HadGEM2-ES & CMIP5 & 336 & 145 & 101 & - & - & 140 & 151 \\
HadGEM3-GC31-LL & CMIP6 & 100 & - & 100 & - & -200 & - & - \\
INM-CM4-8 & CMIP6 & 531 & 165 & 200 & 200 & 100 & 150 & 150 \\
IPSL-CM5A-LR & CMIP5 & 1000 & 156 & 500 & 200 & - & 140 & 260 \\
IPSL-CM6A-LR & CMIP6 & 1200 & 165 & 550 & - & 550 & 150 & 900 \\
MIROC-ES2L & CMIP6 & 500 & 165 & 100 & 100 & 100 & 150 & 150 \\
MIROC-ESM & CMIP5 & 630 & 156 & 100 & 100 & - & 140 & 150 \\
MPI-ESM-P & CMIP5 & 1156 & 156 & 100 & 100 & - & 140 & 150 \\
MPI-ESM1-2-LR & CMIP6 & 1000 & - & 500 & - & - & - & 165 \\
MRI-CGCM3 & CMIP5 & 500 & 156 & 100 & 100 & - & 140 & 150 \\
MRI-ESM2-0 & CMIP6 & 701 & 165 & 200 & - & - & 151 & 151 \\
NESM3 & CMIP6 & 100 & 165 & 100 & - & 100 & 150 & 150 \\
NorESM1-F & CMIP6 & 200 & - & 200 & - & -200 & - & - \\
NorESM2-LM & CMIP6 & 391 & 65 & 100 & - & - & - & 380 \\
UofT-CCSM-4 & CMIP6 & 100 & - & 100 & 100 & - & - & - \\
\hline & & & & & & & - & \\
& & & & & & & & \\
\end{tabular}

bon dioxide concentrations. The abrupt4xCO2 experiment imposes an instantaneous quadrupling of carbon dioxide, to which the coupled climate system is left to equilibrate. The experiment was devised to calculate the climate sensitivity (Gregory et al., 2004). The 1pctCO2 experiment is forced with a carbon dioxide increase of $1 \%$ per year. This compound increase achieves a quadrupling of carbon dioxide after 140 years, but the climate system is still highly transient. This experiment can be used to calculate the transient climate response (Andrews et al., 2012).

The experimental design for the mid-Holocene (midHolocene) and last interglacial (lig127k) simulations is given by Otto-Bliesner et al. (2017). All midHolocene and lig127k simulations should have followed this protocol, such that the only significant differences to their corresponding DECK $p i$ Control simulation are the astronomical parameters and the atmospheric trace greenhouse gas concentrations. In short, astronomical parameters have been prescribed according to orbital constants from Berger and Loutre (1991) and atmo- spheric trace greenhouse gas concentrations are based on recent reconstructions from a number of sources (see Sect. 2.2 in Otto-Bliesner et al. (2017) for details). Note that the different orbital configurations for midHolocene and lig127k result in different seasonal and latitudinal distribution of top-ofatmosphere insolation compared to the DECK piControl. For other boundary conditions, these are either small and locally constrained (e.g. for ice sheets) or there is insufficient spatial coverage to give an informed global estimate (e.g. for vegetation). These other boundary conditions, including solar activity, palaeogeography, ice sheets, vegetation, and aerosol emissions, were therefore kept as identical to each model's DECK piControl simulation. In cases where a boundary condition can either be prescribed or interactive, such as vegetation, the midHolocene and lig $127 k$ simulations followed the setup used in the piControl simulation (Otto-Bliesner et al., 2017).

The Last Glacial Maximum (lgm) simulation is focused on representing the glacial climate of 21000 years ago. Dur- 
ing this period, carbon dioxide concentrations dropped by around $100 \mathrm{ppm}$ and large ice sheets covered the land masses in the northern midlatitudes to high latitudes. The precise specification of the ice coverage and volume varies between the CMIP5 (Abe-Ouchi et al., 2015) and CMIP6 (Kageyama et al., 2017) specifications. Whilst this will impact the teleconnections (Jones et al., 2018), its impact on the tropical Pacific is unclear. The implementation of land-sea changes in regions such as the Maritime Continent is also important (DiNezio et al., 2016).

\subsection{Indices and analysis}

This analysis uses a series of standard metrics and measures to describe the simulated ENSO response. These are achieved using the Climate Variability Diagnostics Package (CVDP; Phillips et al., 2014), which is part of the ESMValTool (Eyring et al., 2016b). This software package has previously been used to explore variability in palaeoclimate simulations, although in the tropical Atlantic rather than $\mathrm{Pa}-$ cific (Brierley and Wainer, 2018). The model output variables required for the analysis are monthly precipitation rate, monthly surface air temperature, and monthly surface temperature. The surface temperature, also known as skin temperature, is utilised to provide SST on the atmospheric grid (Juckes et al., 2020). Prior to undertaking the ENSO analysis, the monthly fields of the palaeoclimate simulations are adjusted to represent the changes in the calendar (i.e. due to changes in the length of months or seasons over time, related to changes in the eccentricity of Earth's orbit and precession), using the PaleoCalAdjust tool (Bartlein and Shafer, 2019).

The mean state of the present-day tropical Pacific is determined using a climatology over the period 1971-2000 for both the historical simulations and observational datasets: the Global Precipitation Climatology Project (GPCP; Adler et al., 2003), the Hadley Centre Sea Ice and Sea Surface Temperature (HadISST; Rayner et al., 2003) and the 20th Century Reanalysis (C20; Compo et al., 2011). For the transient abrupt4xCO2 and 1pctCO2 simulations, the climatology is computed over the final 30 years. For the other quasiequilibrium simulations, all available data are considered to create the climatology. Ensemble mean differences are derived by first calculating the change in climate on each model's grid and then bilinearly interpolating onto a common $1^{\circ}$ by $1^{\circ}$ grid, before averaging across the ensemble members (Brierley and Wainer, 2018).

The state of the tropical Pacific is tracked by the SST anomalies in the NINO3.4 region $\left(5^{\circ} \mathrm{S}-5^{\circ} \mathrm{N}, 120-170^{\circ} \mathrm{W}\right)$ (Trenberth, 1997). The anomalies are computed with respect to each simulation's own climatology, with a linear trend removed. All available years are used to assess and composite the NINO3.4 index (even in the transient simulations with a defined climatological period). This choice maximises the number of ENSO events that can be assessed, although it does require the assumption that changes in the background climatology progress linearly. This assumption is less valid for the abrupt $4 x \mathrm{CO} 2$ experiment than the $1 p c t C O 2$ experiment; however, the ENSO responses show expected coherence across the ensemble, implying the errors introduced are not significant.

The normalised NINO3.4 time series are used to composite all years greater than 1 standard deviation to represent El Niño years and all years less than -1 standard deviation to represent La Niña years (Deser et al., 2010). The standard behaviour of the CVDP is to use December values of the monthly NINO3.4 time series smoothed with a 3-point binomial filter to identify seasons to composite (Phillips et al., 2014). The process is modified here to allow for changes in the seasonal peak of ENSO activity, potentially associated with the orbital variations. Instead of using smoothed December NINO3.4 values to classify ENSO events, the 3month smoothed NINO3.4 time series is calculated for every month, and the maximum anomaly identified for any month (with a year counted from June to May). This added flexibility does not quite replicate the standard behaviour over the period of 1960-2010, because it additionally identifies 1987 as an El Niño that peaked in August. Previous research has accepted this as a valid El Niño event (e.g. Ramanathan and Collins, 1991).

\section{Model evaluation}

The ability of the CMIP5/PMIP3 and CMIP6/PMIP4 models (hereafter, "CMIP" models) used in this study to simulate the present-day SST pattern is first evaluated in comparison with HadISST observations (Rayner et al., 2003) as shown in Fig. 1. Consistent with other studies of coupled GCMs (Bellenger et al., 2014; Collins et al., 2010), the models are generally biased toward overly cold SSTs in the central to western equatorial Pacific. Biases toward overly warm SSTs are present in the far eastern Pacific, again a common feature of GCMs generally resulting from a lack of sufficiently deep stratocumulus decks in eastern boundary regions (see review by Ceppi et al., 2017). The northern subtropics also appear to have similar biases, with colder-than-observed SSTs in the central Pacific and warm biases near the western coast of Mexico. The effect of comparison time period selection is apparent when the historical and piControl simulations are contrasted (Fig. 1c, d versus e, f); the piControl climate is roughly $1{ }^{\circ} \mathrm{C}$ colder on average than the historical simulation, leading to an apparent exacerbation of the cold-tongue bias and reduction in the warm bias in the eastern equatorial Pacific. The tropical Pacific SST biases in the newer CMIP6 models are smaller on average than those in the CMIP5 models (see Fig. S1).

SST biases contribute to errors in the representation of precipitation in the simulations. The Intertropical Convergence Zone (ITCZ) is generally shifted to the north (Fig. 2c, d), leading to a dry bias in the equatorial Pacific, which is partic- 

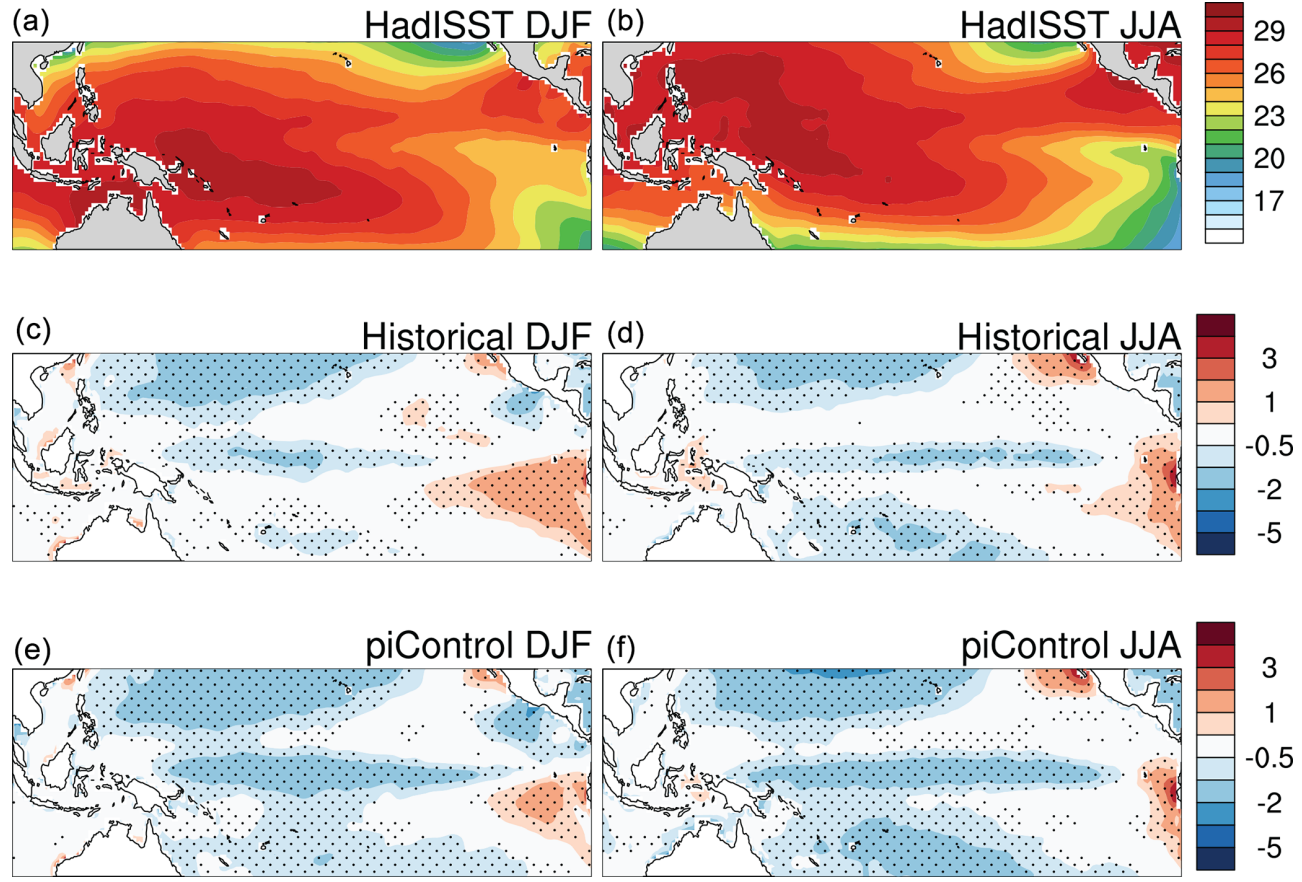

Figure 1. Ability of the ensemble to simulate present-day sea surface temperature (SST) patterns: (a) DJF and (b) JJA SST climatology from HadISST observational dataset (Rayner et al., 2003) between 1971 and 2000, (c) DJF and (d) JJA model ensemble mean SST in historical simulations minus HadISST observations between 1971 and 2000, and (e) DJF and (f) JJA model ensemble mean SST in pre-industrial control simulations minus HadISST observations. Units are ${ }^{\circ} \mathrm{C}$. Stippling indicates that more than two-thirds of the ensemble members agree on the sign of the anomaly.

ularly pronounced during DJF (Fig. 2c). The equatorial cold SST bias also leads to the rising branch of the Walker circulation being shifted to the west, weakening atmospheric feedbacks (Bayr et al., 2018). South of the Equator, there is a wet bias in the location of the climatological South Pacific Convergence Zone (SPCZ) (Fig. 2c, d), consistent with previously documented tendencies for CMIP-class models to produce a so-called "double ITCZ" (Adam et al., 2018; Zhang et al., 2015). Once again, there are substantial differences between precipitation fields in the historical and piControl simulations (Fig. 2c, d versus e, f), with equatorial precipitation generally increased in historical. This is consistent with the expected intensification of the hydrological cycle under climate change (Held and Soden, 2006; Vecchi and Soden, 2007), for which some observational evidence exists during the 20th century (Durack et al., 2012). These differences are confounded somewhat by the slight differences in the composition of the ensembles for piControl and historical simulations (see Table 1). The CMIP6 models simulate smaller biases in tropical Pacific precipitation than CMIP5 models (see Fig. S2), consistent with the improved SST distribution.

The spatial pattern of ENSO sea surface temperature anomalies is illustrated using the ensemble mean difference between composite El Niño and La Niña events, shown in Fig. 3. The magnitude of simulated historical and piControl events (Fig. 3b, c) is quite close to the observed value
(Fig. 3a), with peak SST anomaly values of roughly $2.5^{\circ} \mathrm{C}$. However, the "centre of action" for ENSO is shifted westward relative to observations; this is a known feature of coupled GCMs and is related to the biases in mean SST (Bellenger et al., 2014). Because of this westward shift in the peak of El Niño and La Niña events, the magnitude of SST variability is overly weak in the far eastern Pacific (Fig. 3b, c). There may be substantial variation between the individual model simulations, which is documented elsewhere (e.g. Bellenger et al., 2014). The ENSO SST anomalies in CMIP6 models are stronger than those in CMIP5 models in both the western and eastern equatorial Pacific (see Fig. S3).

We also evaluate the simulation of global temperature teleconnections with ENSO variability (Fig. 4). The observed warming over northern South America, Australia, and much of southeast Asia during DJF of the El Niño event peak (Fig. 4a) is reproduced by the CMIP ensemble mean (Fig. 4c), although the magnitudes of the temperature anomalies appear weaker than observed. The teleconnection to the Atlantic and Indian oceans likewise appears reliable, with comparable magnitudes of surface warming appearing in the models relative to observations. The models appear to have the most difficulty in representing teleconnections to the higher latitudes; the strong warming over northern North America during DJF (Fig. 4a) is significantly underestimated in the models (Fig. 4c, e), as is the cooling over north- 

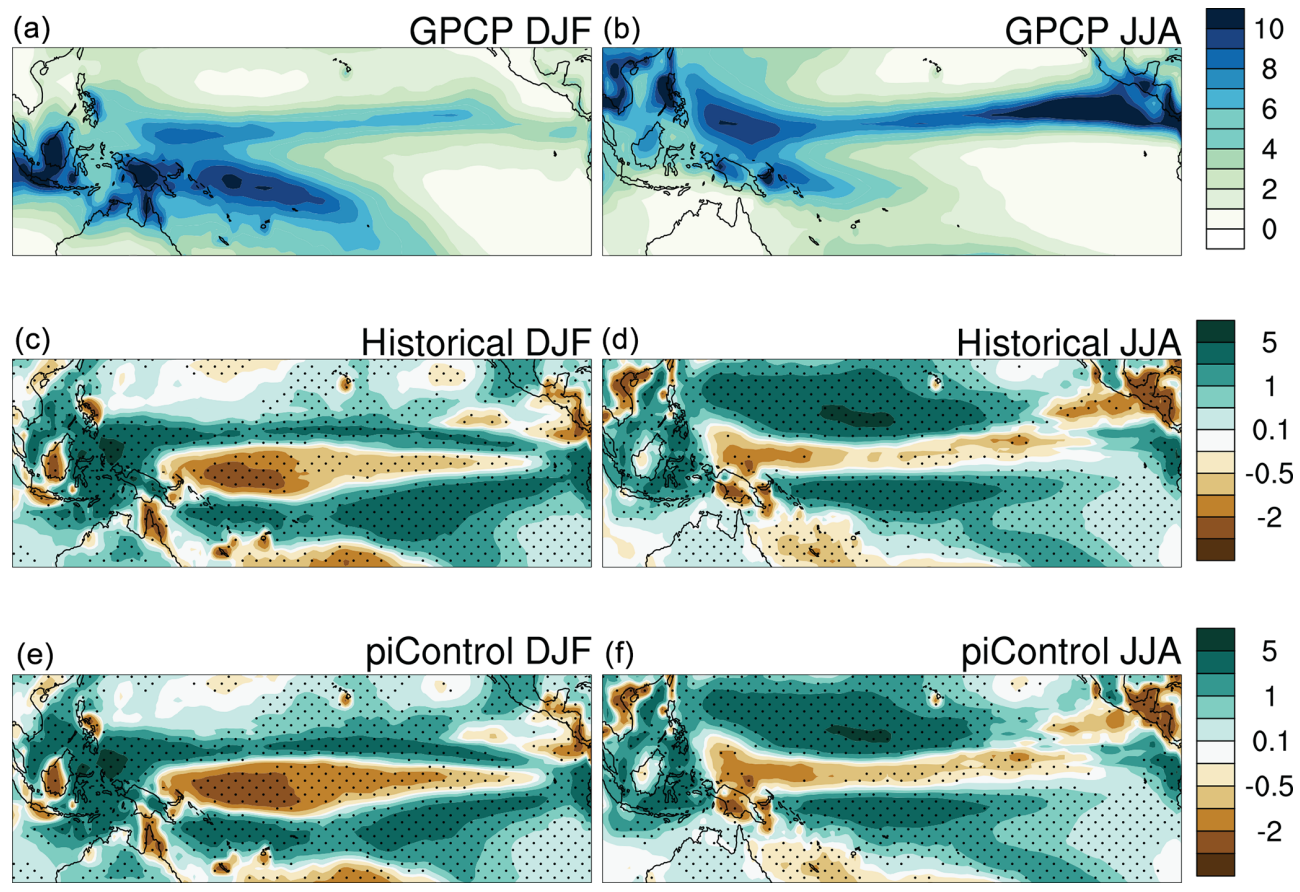

Figure 2. Ability of the ensemble to simulate present-day precipitation patterns: (a) DJF and (b) JJA SST climatology from the GPCP observational dataset (Adler et al., 2003) between 1979 and 1999, (c) DJF and (d) JJA model ensemble mean precipitation in historical simulations minus GPCP observations between 1979 and 1999, and (e) DJF and (f) JJA model ensemble mean precipitation in pre-industrial control simulations minus GPCP observations. Units are $\mathrm{mm} \mathrm{d}^{-1}$. Stippling indicates that more than two-thirds of the ensemble members agree on the sign of the anomaly.

ern Eurasia. The same general tendencies hold during JJA (Fig. 4b, d, f); here, notable model-observation disagreement is apparent over the eastern half of North America, southern South America, and the southwestern Pacific. This latter feature may relate to model difficulties with representing SPCZ dynamics (Brown et al., 2013).

Model performance in simulating ENSO temperature teleconnections is reflected in the structure of ENSO precipitation teleconnection biases, shown in Fig. 5. In DJF, when El Niño events typically peak, drying occurs in the western Pacific warm pool and over the Amazon in the reanalysis (Fig. 5a); this drying persists in JJA but is reduced (Fig. 5b). In both cases, the models underestimate the magnitude of South American precipitation teleconnections; additionally, the western Pacific drying is shifted westward due to the bias in mean SST (Fig. 5c, d). Precipitation teleconnections to North America are overly weak in the simulations during both DJF and JJA, as are the tropical Atlantic anomalies.

In summary, the spatial pattern of ENSO SST variability and the remote teleconnections of temperature and precipitation in response to ENSO are reasonably well simulated in the CMIP models and particularly in the ensemble mean. We therefore examine the changes in ENSO in these models under a range of past and future climate conditions.

\section{Mean state changes}

Changes in the mean state of the tropical Pacific are evaluated for each experiment relative to the piControl simulation. This provides the context for consideration of changes in ENSO amplitude and teleconnections in the subsequent sections. Figures 6 and 7 summarise the seasonal response (DJF and JJA) of the model ensemble to different forcing during the three palaeoclimate experiments (midHolocene, $l g m$, and lig127k) and two idealised future warming scenarios (1pctCO2 and abrupt4xCO2) for surface temperature (Fig. 6) and precipitation (Fig. 7).

For the last interglacial (lig127k), ensemble changes in surface temperatures (Fig. 6e, f) exhibit a strong seasonality that is consistent with lig $127 \mathrm{k}$ minus piControl insolation anomalies (see Otto-Bliesner et al., 2017). More specifically, in JJA, regions located at tropical and subtropical latitudes show warming (of about 0.5 to $2^{\circ} \mathrm{C}$ ). Indeed, during boreal summer, positive insolation anomalies reach their maximum in the Northern Hemisphere (NH) and extend into the tropics and the Southern Hemisphere (SH). In contrast, in DJF, negative insolation anomalies are large in $\mathrm{SH}$ and $\mathrm{NH}$ equatorward of $40^{\circ} \mathrm{N}$, and tropical and subtropical latitudes show cooling (mostly of about $1^{\circ} \mathrm{C}$ ). Similar patterns, although much weaker and spatially constrained, are shown for the midHolocene simulation (Fig. 6a and b for DJF and JJA, re- 
(a)

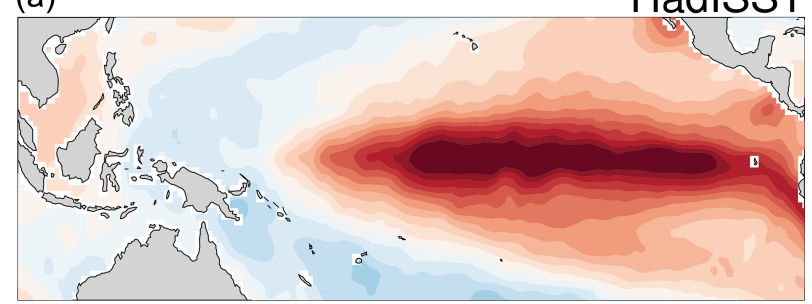

(b)

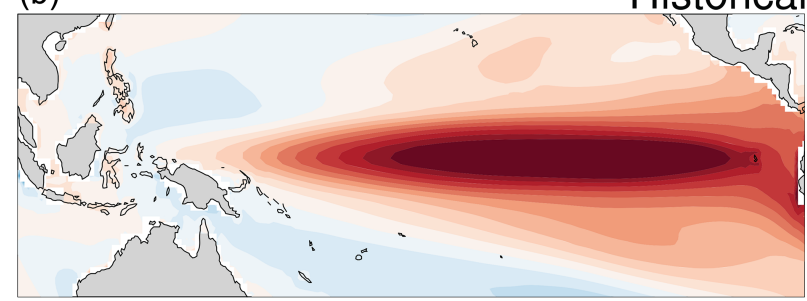

(c)

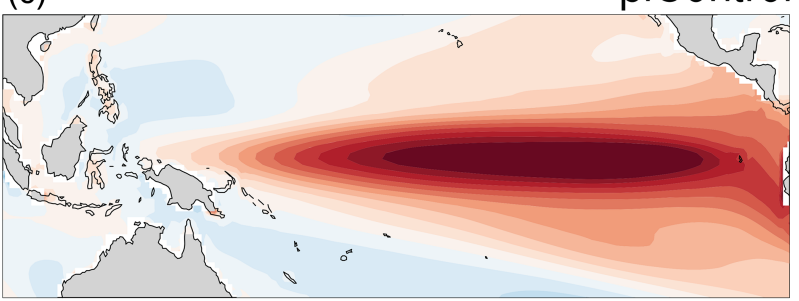

$\begin{array}{lllllllllll}-2 & -1.6 & -1.2 & -0.8 & -0.4 & 0.0 & 0.4 & 0.8 & 1.2 & 1.6 & 2\end{array}$

Figure 3. Evaluation of the ENSO SST anomaly pattern. Composite El Niño minus La Niña sea surface temperature anomaly from (a) the HadISST observational dataset between 1871 and 2012, (b) model ensemble average from the historical simulations between 1850 and 2005 (for CMIP5 models) or 1850 and 2015 (for CMIP6 models), and (c) model ensemble average from the preindustrial control simulations. Units are ${ }^{\circ} \mathrm{C}$.

spectively), with small anomalies in both seasons. A small cooling of $\sim 0.5^{\circ} \mathrm{C}$ is shown over the equatorial regions of the eastern (central) Pacific during DJF (JJA). No warming, however, is shown in the midHolocene simulation in either season. Based on the sign and magnitude of the insolation anomalies for both the midHolocene and (more so) lig127k simulations, the model ensemble mean state changes for both of these simulations are consistent with previous modelling and proxy reconstruction studies (see, e.g. Otto-Bliesner et al., 2013). ${ }^{1}$

The lgm ensemble mean shows cooling of around $2-3{ }^{\circ} \mathrm{C}$ in the tropical Pacific in both DJF and JJA (Fig. 6c, d), consis-

\footnotetext{
${ }^{1}$ Further analysis and description of the results of these PMIP4 experiments can be found in other articles in this special issue e.g. Brierley et al. (2020) for midHolocene and Otto-Bliesner et al. (2020) for lig127k.
}

tent with previous modelling studies and proxy reconstructions (Ballantyne et al., 2005; MARGO Project Members et al., 2009; Masson-Delmotte et al., 2014; Otto-Bliesner et al., 2009). For the idealised future scenarios, the tropical Pacific warms (by $1-3^{\circ} \mathrm{C}$ in the $1 p c t C O 2$ case and more than $3{ }^{\circ} \mathrm{C}$ in the abrupt $4 x \mathrm{CO} 2$ case), with largest warming in the equatorial region. In the case of the abrupt $4 x \mathrm{CO} 2$ simulations, the ensemble mean warming is largest in the eastern and central Pacific, particularly in DJF, whereas the 1pctCO2 ensemble shows enhanced warming extending across the equatorial Pacific. This enhanced equatorial warming is a recognised feature of anthropogenic climate warming (DiNezio et al., 2009; Liu et al., 2005; Xie et al., 2010) and has important implications for ENSO, leading to more frequent extreme $\mathrm{El}$ Niño events in a warmer climate (Cai et al., 2014; Wang et al., 2017).

Regarding ensemble precipitation anomalies, in the lig127k simulations (Fig. 7e, f), the weaker Australian monsoon (drier conditions over northern Australia in DJF) and the enhanced North American monsoon (wetter conditions over northern South America in JJA) are consistent with a northward shift of the mean seasonal position of the ITCZ (over the oceans) and the associated tropical rainfall belt (over the continents). As for surface temperatures, the midHolocene ensemble mean (Fig. 7a, b) shows similar spatial patterns of mean state precipitation change to the lig127k case but with smaller magnitude. The Australian monsoon (North American monsoon) is weaker (stronger) in the midHolocene ensemble mean relative to piControl, just less so than the lig127k simulation. Drying in the midHolocene simulation is larger in the western Pacific than for lig127k. Mechanisms and drivers for precipitation changes over the tropics in last interglacial climates are still unclear and represent an active area of research (see, e.g. Scussolini et al., 2019; Otto-Bliesner et al., 2020).

Precipitation changes in the lgm ensemble (Fig. 7c, d) show a drying over the Maritime Continent, Australia, and southeast Asia. Precipitation in the ITCZ over the tropical Pacific is also reduced, particularly in JJA, in response to cooler SSTs. Precipitation is increased in the western Pacific and on the northern edge of the SPCZ, indicating a northward displacement of the SPCZ, as found in previous studies (Saint-Lu et al., 2015). In the 1 pctCO2 and abrupt $4 x \mathrm{CO} 2$ simulations (Fig. $7 \mathrm{~g}-\mathrm{j}$ ), precipitation increases in the equatorial Pacific where SST warming is greatest (e.g. Chadwick et al., 2013; Xie et al., 2010), with some drying on the northern edge of the ITCZ, particularly in the eastern Pacific. Drying also occurs in the southeast Pacific, where warming is relatively small and trade winds are intensified, leading to drying of the eastern edge of the SPCZ in DJF (Brown et al., 2013; Widlansky et al., 2013).

Previous studies have noted that changes in tropical precipitation are strongly influenced by the spatial pattern of SST change (Chadwick et al., 2013; Xie et al., 2010). Such changes in SST gradients are also linked to changes in the 

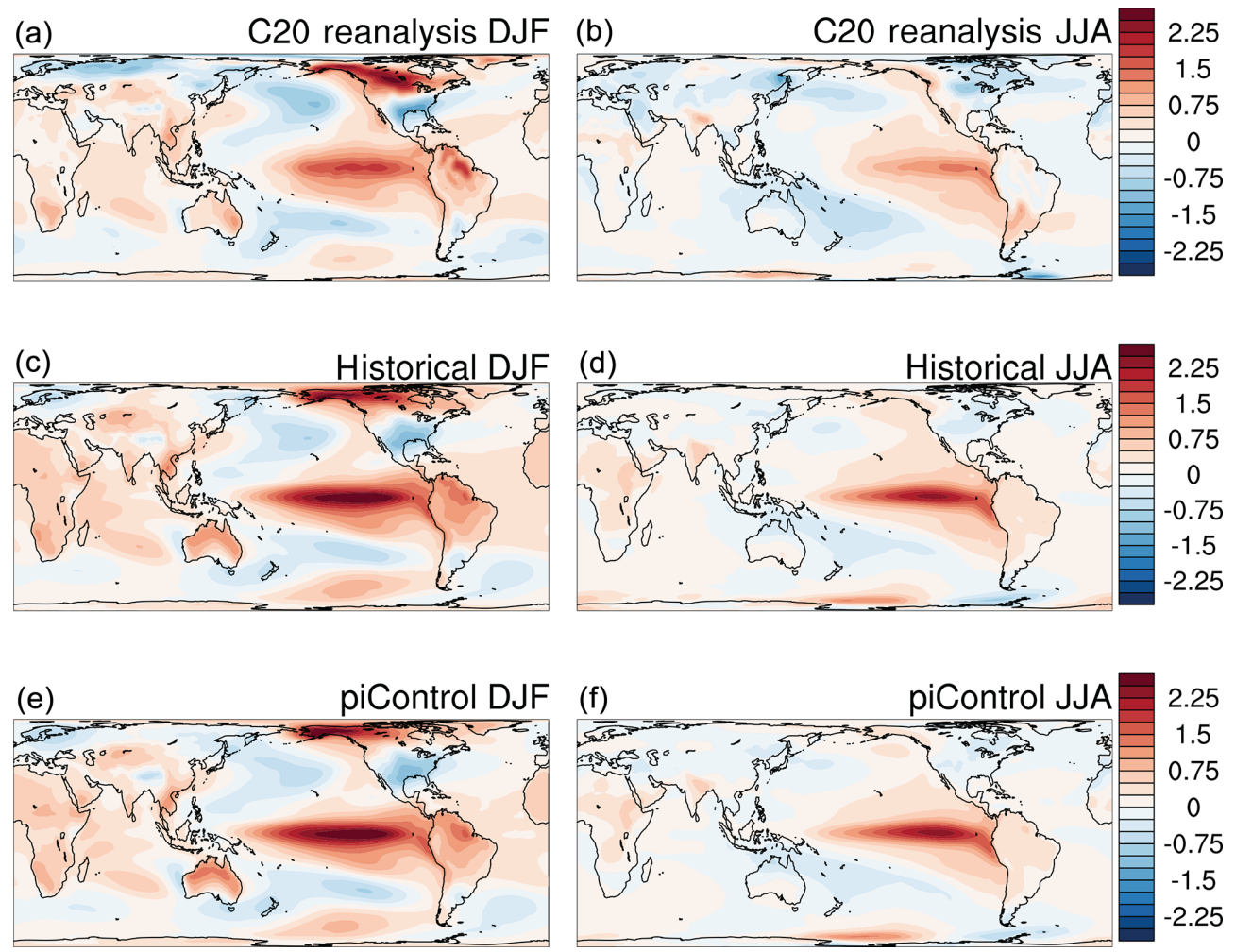

Figure 4. Evaluation of the ENSO temperature teleconnections. Composite El Niño minus La Niña surface temperature anomaly from (a) DJF and (b) JJA from the C20 reanalysis (Compo et al., 2011) between 1871 and 2010, (c) DJF and (d) JJA model ensemble mean from the historical simulations between 1850 and 2005 (for CMIP5 models) or 1850 and 2015 (for CMIP6 models), and (e) DJF and (f) JJA model ensemble mean from the pre-industrial control simulations. Units are ${ }^{\circ} \mathrm{C}$.

Walker circulation (Bayr and Dommenget 2013; Bayr et al., 2014). We therefore also plot the relative SST change, with the mean over the tropical domain $\left(25^{\circ} \mathrm{N}-25^{\circ} \mathrm{S}, 100^{\circ} \mathrm{E}-\right.$ $\left.80^{\circ} \mathrm{W}\right)$ subtracted, in Fig. S4. Comparison of the precipitation changes in Fig. 7 and the relative SST changes in Fig. S4 confirms that there is generally close agreement, with regions of relative warming experiencing increased precipitation and regions of relative cooling becoming drier in the ensemble mean.

\section{ENSO amplitude changes}

The amplitude of ENSO, as measured by the standard deviation of SST from the NINO3.4 region, is shown for each model in each experiment in Fig. 8. The amplitudes of ENSO in the piControl simulation from each model are also shown for reference. The percentage change in ENSO amplitude in the experiments relative to piControl is shown in Fig. 9, and the ensemble mean change and minimum and maximum model changes are given in Table 2.

In the midHolocene simulations, a large majority (26 out of 30) of models show a decrease in ENSO variability, with the only exceptions being CMIP5 models (CSIRO-Mk3-60 and MRI-CGCM3) and CMIP6 models (INM-CM4-8 and
NorESM2-LM). Most of these changes are small, however, with few models showing more than a $\sim 20 \%$ decrease (Figs. 8a and 9a). This is consistent with previous model studies, which generally show a smaller reduction in midHolocene ENSO amplitude than implied by proxy records (e.g. Emile-Geay et al., 2016), as discussed in Sect. 1. A similarly consistent reduction in ENSO amplitude is found for the lig127k simulations (Figs. 8c and 9c), with 10 out of 12 models showing a reduction in amplitude, typically of at least $20 \%$.

In contrast, a much less consistent response is found for the lgm, $1 p c t C O 2$, and abrupt $4 x \mathrm{CO} 2$ simulations. In all of these simulations, the sign of change in amplitude of ENSO is approximately equally spread between increases and decreases across the set of models. In the $\operatorname{lgm}$ simulations (Figs. 8b and 9b), some models (e.g. FGOALS-g2) show a large decrease in variability of over $40 \%$ and others (e.g. IPSL-CM5A-LR) show large increases of up to $\sim 40 \%$. Likewise, in the 1pctCO2 simulations (Figs. 8d and 9d), ENSO variability is again highly model dependent, with the range including large decreases of over $\sim 20 \%$ in some models (e.g. CCSM4) to large increases of up to $\sim 40 \%$ in others (e.g. MPI-ESM-P). The same is true for the abrupt $4 x \mathrm{CO} 2$ simulations (Figs. 8e and 9e), with the range including large 

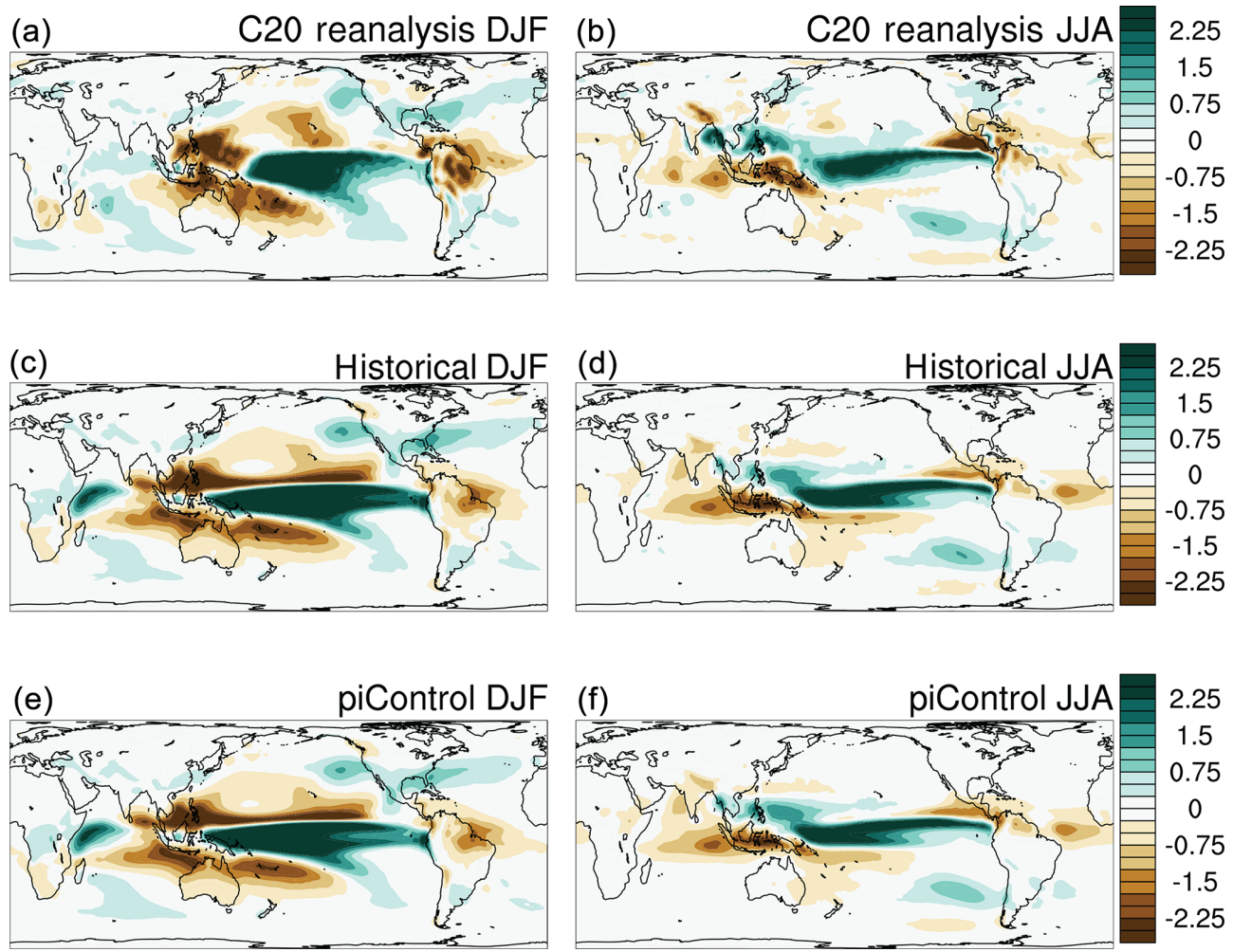

Figure 5. Evaluation of the ENSO precipitation teleconnections. Composite El Niño minus La Niña precipitation anomaly from (a) DJF and (b) JJA from the C20 reanalysis (Compo et al., 2011) between 1871 and 2010, (c) DJF and (d) JJA model ensemble mean from the historical simulations between 1850 and 2005 (CMIP5)/2015 (CMIP6), and (e) DJF and (f) JJA model ensemble mean from the pre-industrial control simulations. Units are $\mathrm{mm} \mathrm{d}^{-1}$.

Table 2. Multi-model mean change in ENSO amplitude (\%) based on NINO3.4 standard deviation for each experiment relative to the preindustrial control for all models, CMIP5/PMIP3 models, and CMIP6/PMIP4 models. Note that CMIP5/PMIP3 does not include lig127k experiment. Values in brackets for all models are the minimum and maximum model values.

\begin{tabular}{lrrrrr}
\hline Experiment & $\begin{array}{r}\text { All models' } \\
\text { ENSO } \\
\text { change \% }\end{array}$ & $\begin{array}{r}\text { CMIP5 } \\
\text { ENSO } \\
\text { change \% }\end{array}$ & $\begin{array}{r}\text { CMIP5 } \\
\text { number } \\
\text { models }\end{array}$ & $\begin{array}{r}\text { CMIP6 } \\
\text { ENSO } \\
\text { change \% }\end{array}$ & $\begin{array}{r}\text { CMIP6 } \\
\text { number } \\
\text { models }\end{array}$ \\
\hline midHolocene & $-8.4(-36.8$ to 18.5$)$ & -6.9 & 14 & -9.7 & 16 \\
lgm & $-4.8(-46.9$ to 32.5) & -4.7 & 9 & -4.8 & 3 \\
lig127k & $-20.6(-54.2$ to 10.3$)$ & - & - & -20.6 & 12 \\
lpctCO2 & $5.6(-33.2$ to 34.1$)$ & 1.4 & 13 & 11.6 & 9 \\
abrupt4xCO2 & $2.2(-46.3$ to 57.7$)$ & 3.0 & 12 & 1.4 & 11 \\
\hline
\end{tabular}

decreases of over $\sim 40 \%$ in some models (e.g. GISS-E2-R) to large increases of up to $\sim 50 \%$ in others (e.g. CSIROMk3-6-0). This is consistent with previous studies showing little agreement on future projections of ENSO amplitude change (Collins et al., 2010, 2014).

Comparing the absolute magnitudes of ENSO amplitude in all simulations (Fig. 8), the standard deviation ranges (i.e. between the models showing the smallest and largest standard deviations) are $\sim 0.7^{\circ} \mathrm{C}$ in the midHolocene, $\sim 1.1^{\circ} \mathrm{C}$ in the lgm, $\sim 0.2^{\circ} \mathrm{C}$ in the lig $127 \mathrm{k}, \sim 0.7^{\circ} \mathrm{C}$ in the $1 p c t C O 2$, and $\sim 1{ }^{\circ} \mathrm{C}$ in the abrupt $4 x \mathrm{CO} 2$ simulations. The cold cli- mate simulation and the extreme future run therefore show the largest spread between models, suggesting a lack of model agreement, whereas the midHolocene and lig127k simulations as well as the gradual future run have a much smaller spread between models.

Comparing the change in ENSO amplitude in all simulations (Fig. 9), we find that the midHolocene and lig $127 k$ simulations have high inter-model agreement on the sign of the response, consistently showing lower ENSO variability relative to the piControl simulation in both cases. The common factor between these simulations is the change in seasonal- 

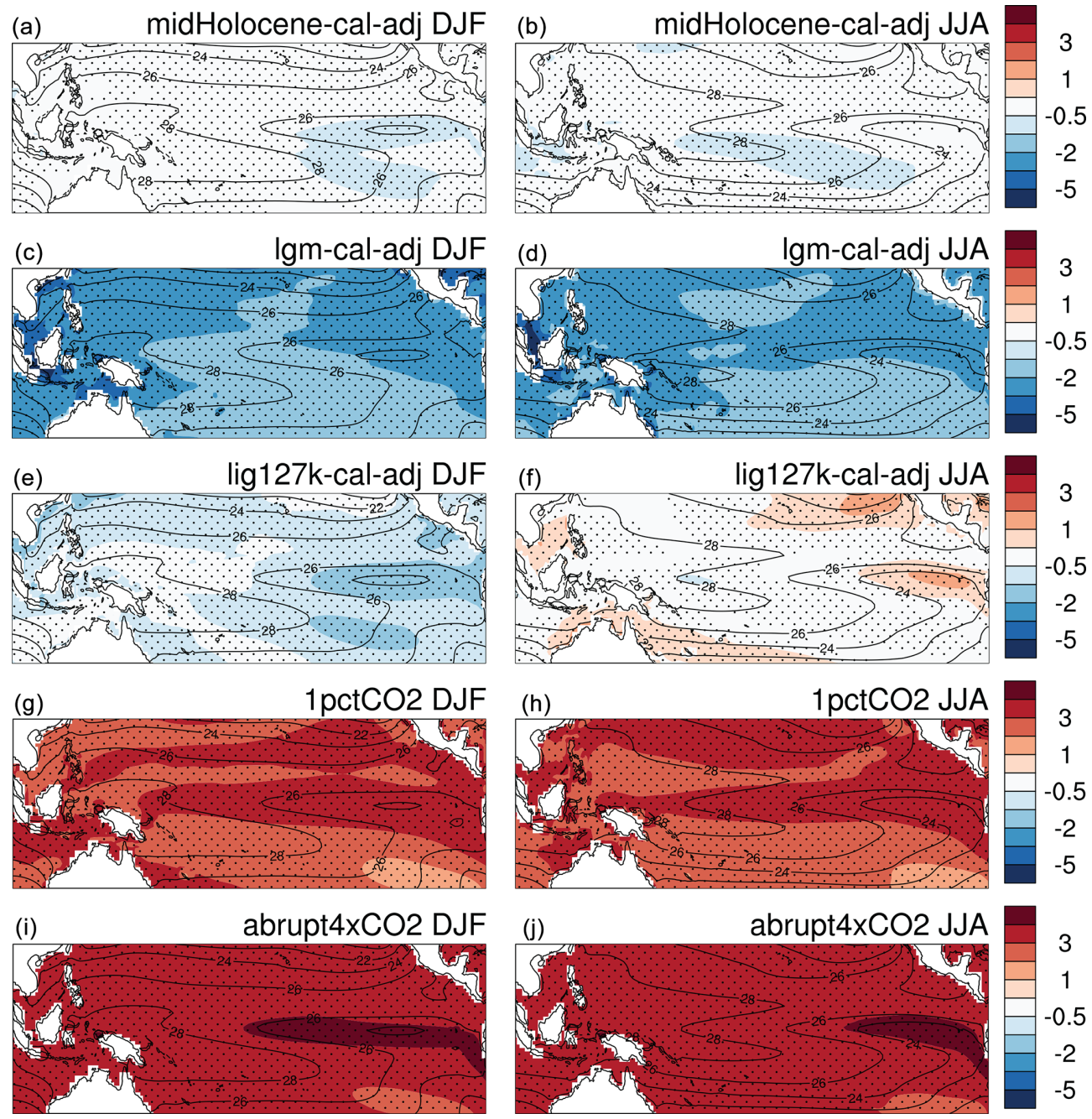

Figure 6. Ensemble mean seasonal changes in sea surface temperature in experiment minus pre-industrial control simulations: (a) DJF midHolocene, (b) JJA midHolocene, (c) DJF lgm, (d) JJA lgm, (e) DJF lig127k, (f) JJA lig127k, (g) DJF 1pctCO2, (h) JJA 1pctCO2, (i) DJF abrupt4xCO2, and (j) JJA abrupt4xCO2. The ensemble mean temperature pattern in the pre-industrial control simulations is shown as black contours. Units are ${ }^{\circ} \mathrm{C}$. Stippling indicates that more than two-thirds of the ensemble members agree on the sign of the change.

ity of insolation, which in both cases is increased in boreal summer, leading to a damped ENSO via a range of mechanisms discussed in Sect. 1 and also Sect. 7. In contrast, there is much less inter-model agreement in the cold climate simulation (i.e. the $\operatorname{lgm}$ simulation) and the gradual and extreme future warming runs (i.e. the lpctCO2 and abrupt $4 x \mathrm{CO} 2$ simulations, respectively). While the model NINO3.4 time series have been detrended to remove long-term trends, the standard deviations shown in Figs. 8 and 9 may also include contributions from variability at frequencies higher and lower than the ENSO range. These could be removed using a band-pass filter with a 2- to 8-year window to isolate ENSO frequencies. Band-pass filtering reduces the amplitude of NINO3.4 variability in each simulation (not shown) but does not substantively alter the direction or magnitude of changes in ENSO amplitude for any of the experiments (see Fig. S5).

Comparison of ENSO amplitude changes in CMIP5 and CMIP6 model ensembles shows generally strong agreement between the two generations of models (see Table 2 and Fig. S6). The ensemble mean reduction in midHolocene ENSO strength is somewhat greater for CMIP6 models than it is for CMIP5 models, while there is no lig $127 k$ experiment in CMIP5. Both sets of models simulate weaker ENSO amplitude on average in the lgm experiments, although there are only three CMIP6 models available for this experiment. Both CMIP5 and CMIP6 models simulate an ensemble mean increase in ENSO amplitude in the idealised future 1pctCO2 and abrupt $4 x \mathrm{CO} 2$ experiments, although with large intermodel spread (see Figs. 9 and S6). 

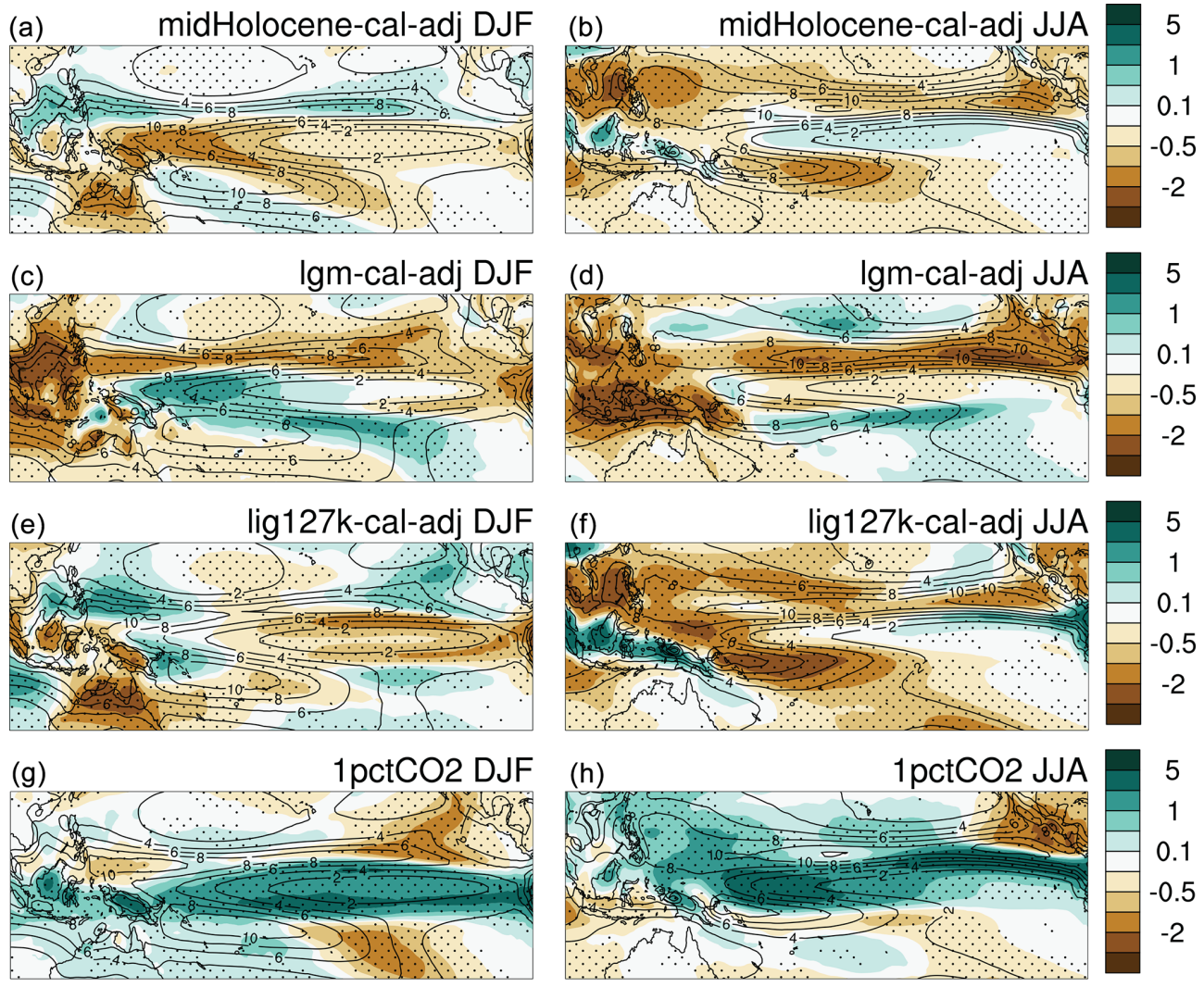

(i)

abrupt4xCO2 DJF
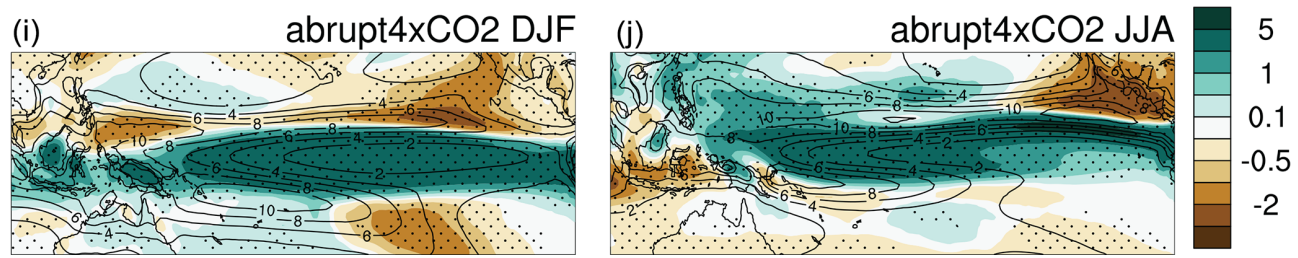

Figure 7. Ensemble mean seasonal changes in precipitation in experiment minus pre-industrial control simulations: (a) DJF midHolocene, (b) JJA midHolocene, (c) DJF lgm, (d) JJA lgm, (e) DJF lig127k, (f) JJA lig 127k, (g) DJF 1pctCO2, (h) JJA 1pctCO2, (i) DJF abrupt4xCO2, and (j) JJA abrupt4xCO2. The ensemble mean temperature pattern in the pre-industrial control simulations is shown as black contours. Units are $\mathrm{mm} \mathrm{d}^{-1}$. Stippling indicates that more than two-thirds of the ensemble members agree on the sign of the change.

\section{ENSO patterns and teleconnections}

The anomalous pattern of El Niño minus La Niña SST composite for each experiment relative to piControl (see Fig. 3c) is shown in Fig. 10. The midHolocene and lig127k patterns (Fig. 10a, c) show negative SST anomalies in the central equatorial Pacific, indicating weakening of event amplitude, consistent with the average weakening of ENSO variability in these experiments (see Sect. 5 and Fig. 9). There is a much larger weakening of SST variability in the lig $127 k$ than the midHolocene case. The lgm SST pattern (Fig. 10b) shows negative anomalies in the central to western Pacific, indicating either an eastward shift of the ENSO pattern and/or weaker central Pacific variability. On the other hand, both the 1 pctCO2 and abrupt4xCO2 composites (Fig. 10d, e) show positive Pacific SST anomalies associated with ENSO at the Equator, with the largest values in the central $\mathrm{Pa}$ cific, and high model agreement. This suggests an increased ENSO variability among the ensemble, particularly for the abrupt $4 x \mathrm{CO} 2$ simulations, despite the disagreement between model ENSO amplitude changes discussed in Sect. 5.

The global temperature and precipitation teleconnections with ENSO for each experiment relative to piControl are shown in Figs. 11 and 12. As discussed above, both lig127k and midHolocene simulations show weaker ENSO SST variability relative to piControl (Fig. 10a, c). The lig127k simulations have a much greater weakening of the ENSO SST and temperature patterns (Figs. 10c and 11e, f) than any of the other simulations (although based on a small number of models), with cooler SSTs in the central Pacific. The midHolocene ENSO SST and temperature pattern (Figs. 10a and $11 \mathrm{a}, \mathrm{b})$ is a weaker version of the lig $127 \mathrm{k}$ response. 
(a) midHolocene

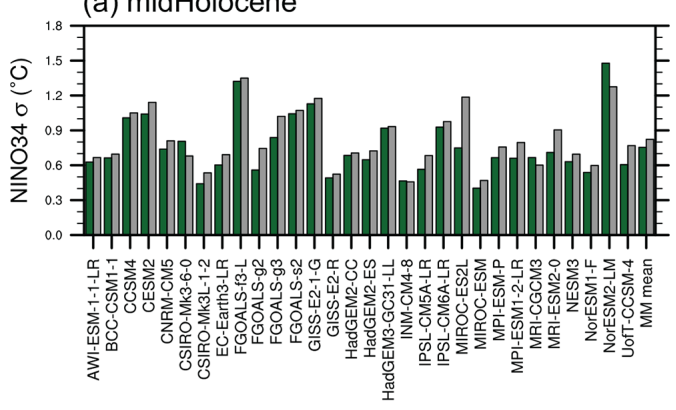

(c) lig127k

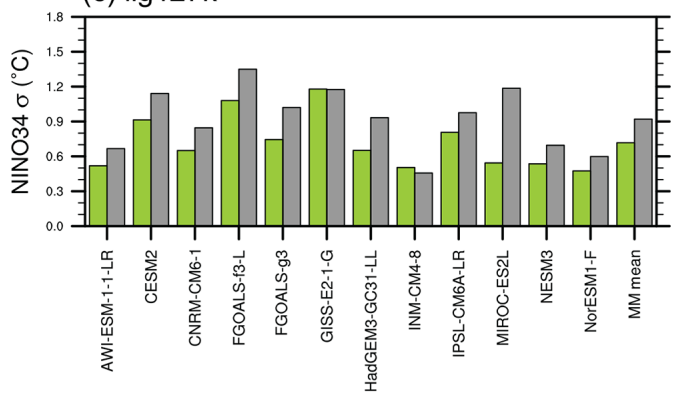

(e) abrupt $4 \times \mathrm{CO} 2$

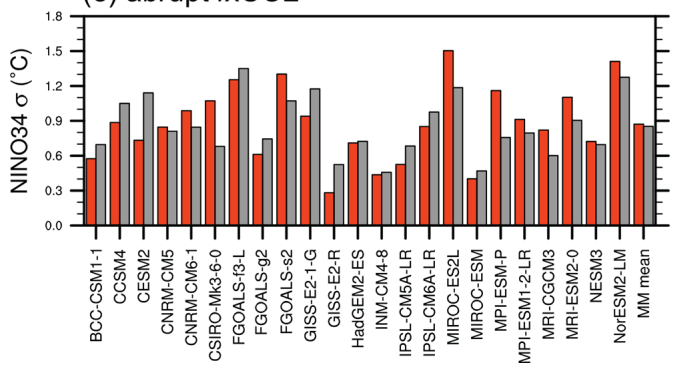

(b) $\operatorname{lgm}$

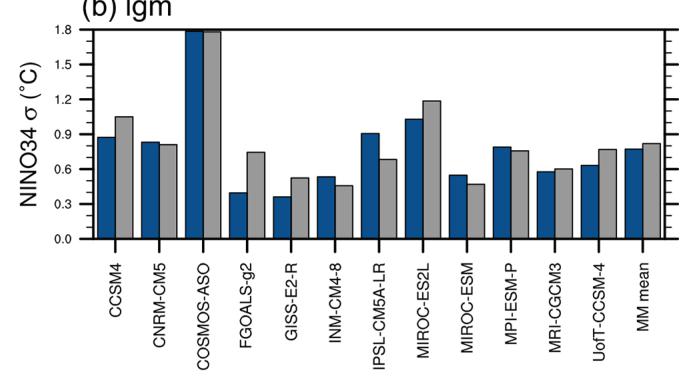

(d) $1 \mathrm{pctCO} 2$

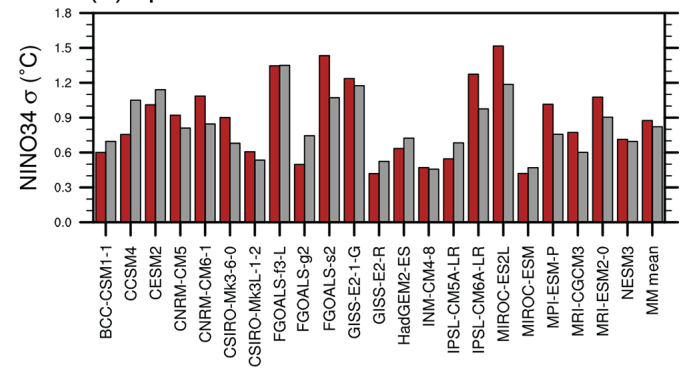

Figure 8. Amplitude of ENSO measured from standard deviation of NINO3.4 index $\left({ }^{\circ} \mathrm{C}\right)$ in piControl simulations (grey bars) and (a) midHolocene (dark green bars), (b) lgm (blue bars), (c) lig127k (light green bars), (d) 1pctCO2 (dark red bars), and (e) abrupt4xCO2 (light red bars) simulations. Model names are given below plots. Multi-model (MM) mean is also shown.

The ENSO precipitation teleconnection in the lig $127 k$ simulations (Fig. 12e, f) consists of a weakening of the piControl ENSO precipitation pattern, with much drier conditions in the equatorial Pacific and over the SPCZ during El Niño events. The midHolocene ENSO precipitation pattern (Fig. 12a, b) is again a weaker version of the lig $127 k$ ENSO precipitation response.

The lgm simulations show cooler SSTs in the western tropical Pacific in the ENSO composite (Fig. 10b), consistent with a weakening of ENSO variability in this region. Cool anomalies over Australia and warm anomalies over North America are also evident (Fig. 11c, d). As expected, given the colder global mean temperatures (Fig. 6), precipitation associated with ENSO is reduced in the tropical Pacific and the overall hydrological cycle is weaker (Fig. 12c, d). Remote responses include wetter conditions over Australia and drier conditions over North America, somewhat resembling a La Niña pattern, although with low model agreement.
In contrast to the lgm experiments, the $1 p c t C O 2$ and abrupt $4 x \mathrm{CO} 2$ simulations are much warmer than the other experiments (Fig. 6). The largest temperature anomalies are seen for the abrupt4xCO2 simulations (Fig. 11i, j), which also had increased amplitude of SST variability in the central Pacific (Fig. 10e). The abrupt4xCO2 experiment shows warmer temperatures globally during El Niño events, particularly over continents and high northern latitudes (except Greenland in DJF). It is possible that elements of the pattern in this experiment arise from the linear detrending failing to sufficiently remove the transient changes in mean state (Sect. 2.3). The 1pctCO2 simulations (Fig. 11g, h) show a similar but much weaker response. The precipitation response to ENSO (Fig. 12) is enhanced in the abrupt $4 x \mathrm{CO} 2$ and 1 pctCO2 simulations relative to piControl, with increases in precipitation in the equatorial Pacific and decreases in the subtropics, as ENSO influences tropical atmospheric circulation and therefore the hydrological cycle 
(a) midHolocene

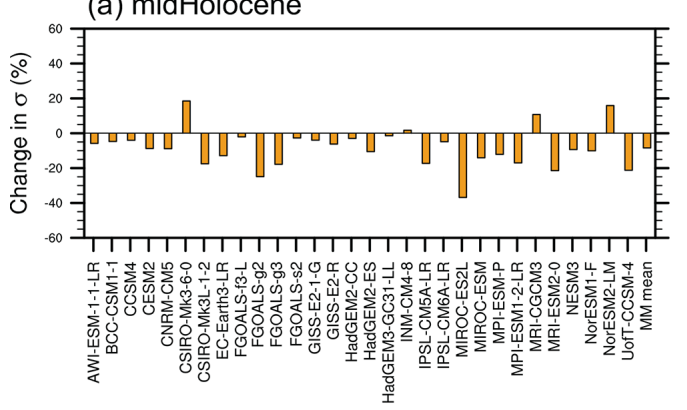

(c) $\operatorname{lig} 127 \mathrm{k}$

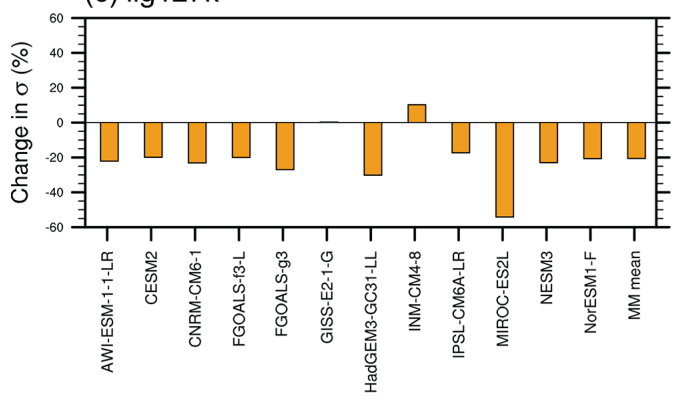

(e) abrupt4xCO2

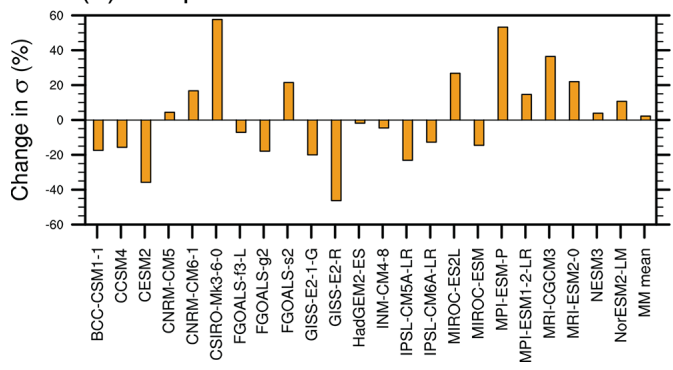

(b) lgm

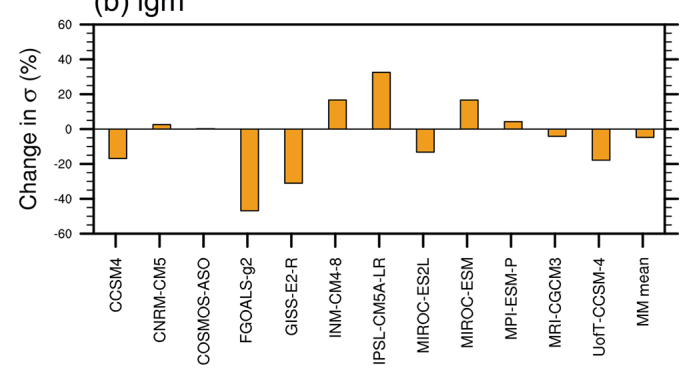

(d) 1 pctCO2

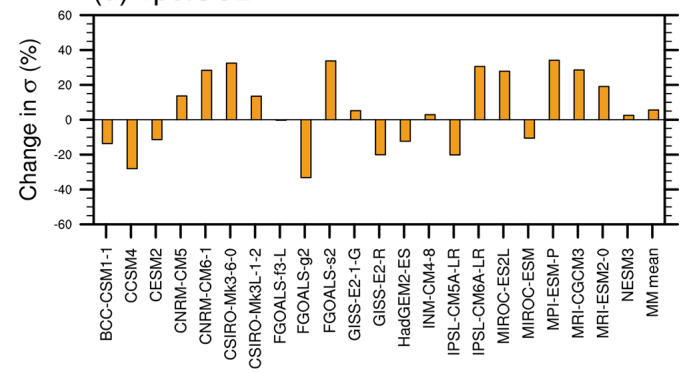

Figure 9. Change in amplitude of ENSO measured from standard deviation of NINO3.4 index relative to piControl amplitude (\%) in (a) midHolocene, (b) lgm, (c) lig127k, (d) 1pctCO2, and (e) abrupt4xCO2. Model names are given below plots. MM mean is also shown.

(Lu et al., 2008; Nguyen et al., 2013). This is consistent with previous studies showing intensified ENSO temperature and precipitation impacts in a warmer climate (e.g. Power et al., 2013; Power and Delage, 2018).

The relationship between changes in ENSO and changes in the annual cycle, zonal and meridional SST gradient are investigated for all models and experiments (Fig. 13). The change in ENSO amplitude based on the standard deviation of NINO3.4 (relative to piControl) is plotted against the change in annual cycle of NINO3.4 SST in Fig. 13a, with a weak positive correlation between the two variables. The change in ENSO amplitude was found to have no significant correlation with the change in equatorial Pacific zonal SST gradient (defined as $5^{\circ} \mathrm{S}-5^{\circ} \mathrm{N}, 150^{\circ} \mathrm{E}-170^{\circ} \mathrm{W}$ minus $5^{\circ} \mathrm{S}-$ $5^{\circ} \mathrm{N}, 120-90^{\circ} \mathrm{W}$ ), shown in Fig. 13b. Finally, the relationship between eastern Pacific rainfall and meridional SST gradient (Cai et al., 2014) is investigated (Fig. 13c). The meridional SST gradient in the eastern Pacific is defined as the average SST over the off-equatorial region $\left(5-10^{\circ} \mathrm{N}, 150\right.$ $\left.90^{\circ} \mathrm{W}\right)$ minus the average over the equatorial region $\left(2.5^{\circ} \mathrm{S}-\right.$ $\left.2.5^{\circ} \mathrm{N}, 150-90^{\circ} \mathrm{W}\right)$. The strength of eastern Pacific El Niño rainfall is represented as the changes in ENSO composite precipitation over the $\mathrm{NINO} 3$ region $\left(5^{\circ} \mathrm{S}-5^{\circ} \mathrm{N}, 150-90^{\circ} \mathrm{W}\right)$ normalised by the NINO3.4 standard deviation used to identify the composited events. This normalisation aims to remove the impact of the changes in ENSO variability documented between the experiments (e.g. Power and Delage, 2018). The significant negative correlation is consistent with the analysis demonstrated by Cai et al. (2014) and Collins et al. (2019), but this analysis approach allows the relationship to be visualised across many more simulations and experiments. This relationship appears to be fundamental feature of ENSO behaviour rather than just a response to greenhouse gas forcing. 

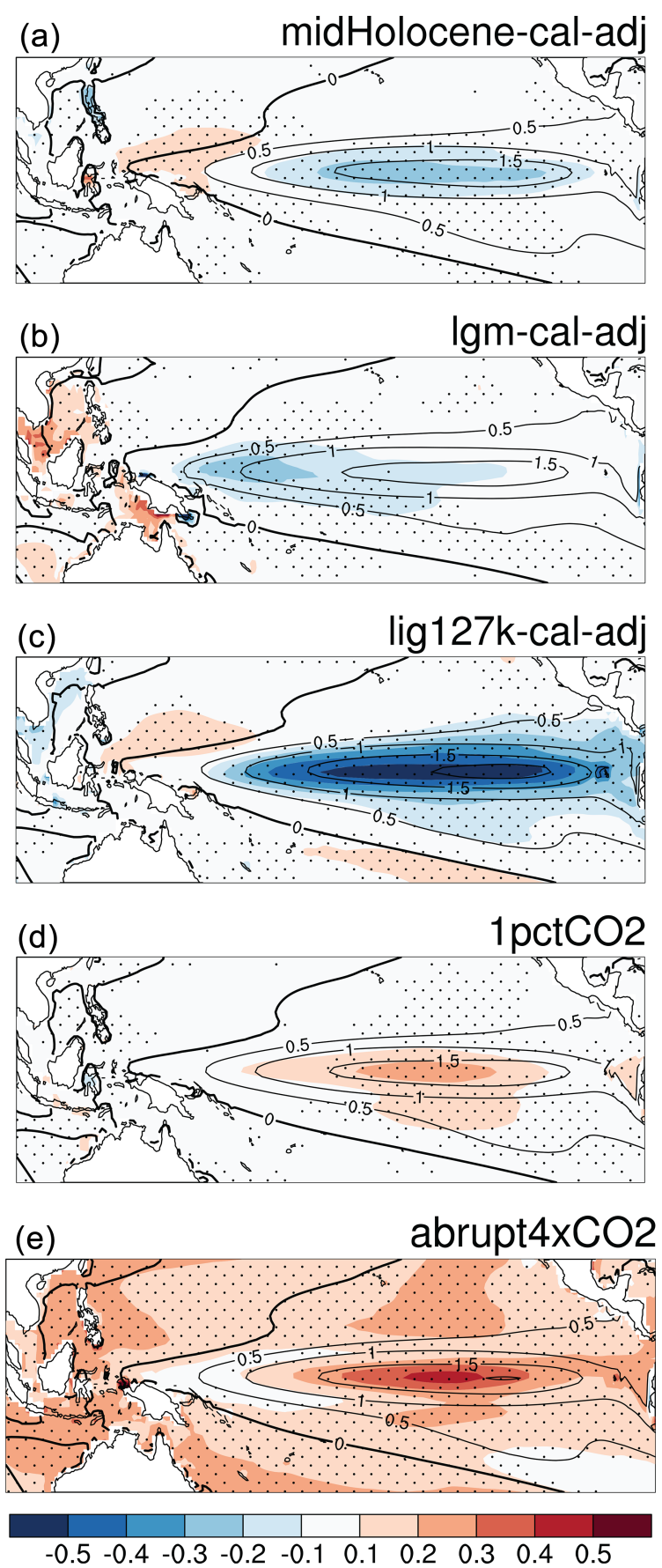

Figure 10. The changes in the SST pattern associated with ENSO in each experiment compared with piControl. The ensemble mean difference between the SST composites of each model's El Niño minus La Niña (defined as \pm 1 standard deviation) in the (a) midHolocene, (b) lgm, (c) lig127k, (d) 1pctCO2, and (e) abrupt4xCO2 experiments minus the same pattern for the piControl simulations is shown. The ensemble mean ENSO SST patterns in the piControl simulations are shown as black contours. Stippling indicates that more than two-thirds of the ensemble members agree on the sign of the change.

\section{Mechanisms and discussion}

There is evidence that the mid-Holocene, a period of suppressed ENSO variability, featured a stronger zonal gradient in the tropical Pacific mean SST than the 20th century, namely "La Niña-like conditions" (Barr et al., 2019; Gagan and Thompson, 2004; Koutavas et al., 2002; Luan et al., 2012; Shin et al., 2006). In contrast, proxy records suggest that the mean state of the tropical Pacific during the Pliocene warm period featured sustained El Niño-like conditions ( $\mathrm{Fe}$ dorov et al., 2006; Wara et al., 2005). It is likely that the weak zonal SST gradient in the Pliocene was less favourable for ENSO occurrence (Brierley, 2013; Manucharyan and Fedorov, 2014). These contradictory responses imply that the dynamical mechanisms determining the relationship between the zonal gradient in mean SST and ENSO amplitude (e.g. Sadekov et al., 2013) must consist of several processes. The relationship between ENSO amplitude and SST gradient may also be nonlinear (Hu et al., 2013). This lack of consistent or linear relationship between zonal SST gradient and ENSO amplitude is supported by the results presented here, shown in Fig. 13b.

During the mid-Holocene, the reduced tropical insolation led to the cooling of the tropical Pacific, directly producing a La Niña-like condition. Under La Niña-like conditions, the air-sea coupling strength is reduced due to a suppressed convective instability, and thus ENSO variability is suppressed (Liu et al., 2000; Roberts et al., 2014). The stronger seasonality in insolation over the Northern Hemisphere associated with the precession cycle resulted in a stronger annual cycle, which could also act to reduce ENSO variability through the intensified annual-frequency entrainment (Liu, 2002; Pan et al., 2005). A similar but stronger precession effect due to the higher eccentricity during the last interglacial period was also found to have a relatively weak ENSO amplitude in palaeoproxy records (Hughen et al., 1999; Tudhope et al., 2001) and climate model simulations (An et al., 2017; Salau et al., 2012). However, the mid-Holocene simulations of PMIP $2 / 3$ mostly showed a reduction of both annual cycle and ENSO amplitude (An and Choi, 2014; Masson-Delmotte et al., 2014).

The reduced annual cycle over the tropical eastern $\mathrm{Pa}$ cific is attributed to the relaxation of eastern Pacific upperocean stratification due to the annual downwelling Kelvin wave forced by western Pacific wind anomalies (Karamperidou et al., 2015) or the deepening of ocean mixed layer depth associated with the northward shift of the ITCZ (An and Choi, 2014). Therefore, the mid-Holocene ENSO variability in PMIP2/3 may be deemed to the result of the counterbalance between the reduction due to the weaker air-sea coupling and the intensification due to the reduced frequency entrainment (An and Choi, 2014). Other factors may include coupling of the circulation in the eastern Pacific with the North American monsoon (implying dynamical damping of upwelling in the eastern Pacific) and an increased southeast 

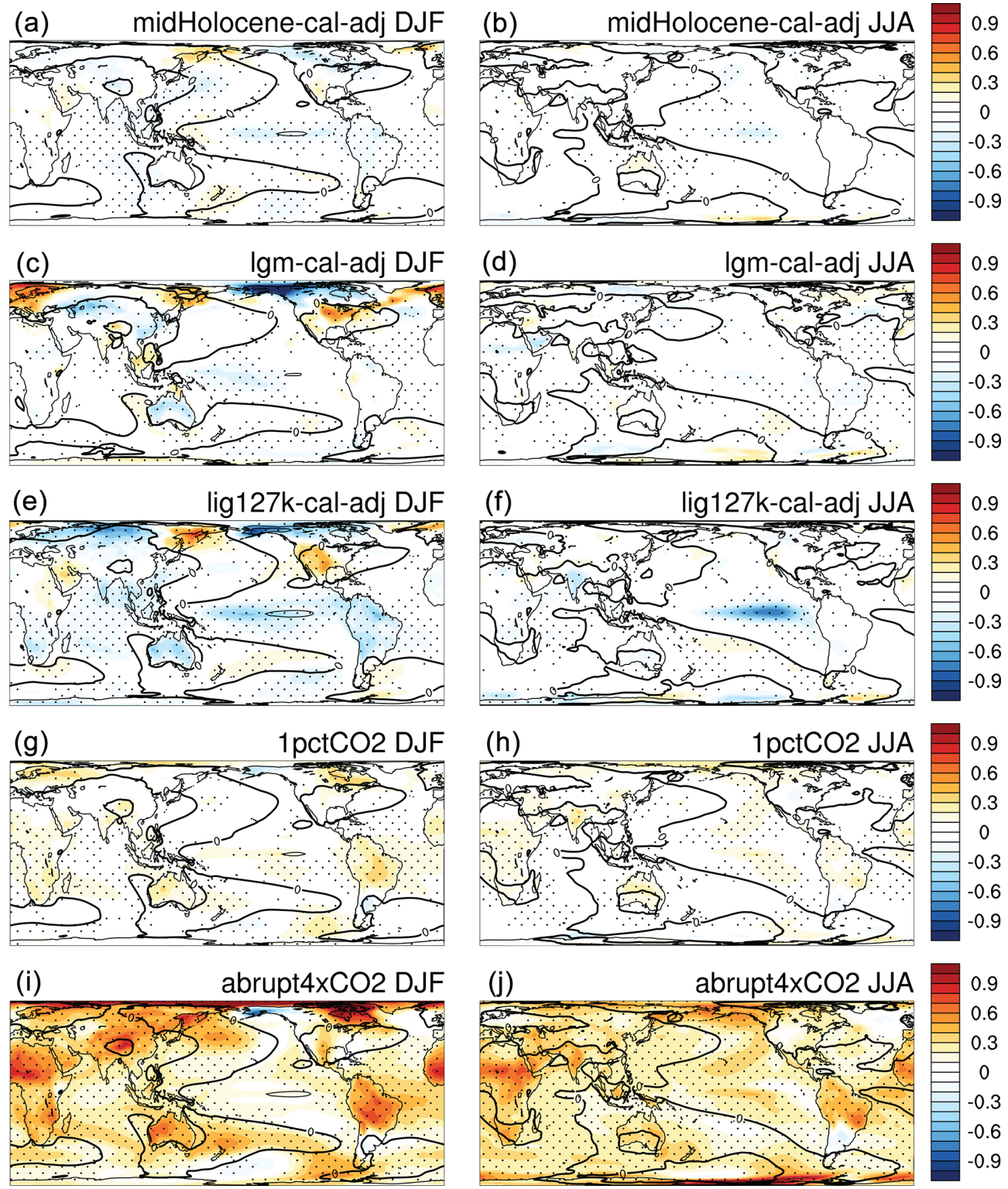

Figure 11. The changes in the seasonal temperature teleconnection pattern associated with ENSO in each experiment compared with the pre-industrial control. The ensemble mean difference between the surface temperature composites of each model's El Niño minus La Niña (defined as \pm 1 standard deviation) in the $(\mathbf{a}, \mathbf{b})$ midHolocene, $(\mathbf{c}, \mathbf{d}) \operatorname{lgm},(\mathbf{e}, \mathbf{f}) \operatorname{lig} 127 \mathrm{k},(\mathbf{g}, \mathbf{h}) 1$ pctCO2, and (i, j) abrupt4xCO2 experiments minus the same pattern for the piControl simulations is shown. The ensemble mean ENSO patterns in the piControl simulations are shown as black contours. Stippling indicates that more than two-thirds of the ensemble members agree on the sign of the change.

Asian monsoon which strengthens winds in the western Pacific. Alternatively, An et al. (2010) and An and Choi (2013) argue that the change in annual cycle amplitude is not a cause of change in ENSO amplitude; it is the changes in the mean climate state that modify both the ENSO and annual cycle amplitudes in the opposite way. The analysis presented here would appear to support the argument that there is no consistent relationship between changes in the amplitude of the annual cycle and changes in the ENSO variability (Fig. 13a).
ENSO variability can be suppressed or enhanced by remote forcing. For example, the enhanced Asian summer monsoon also leads to La Niña-like conditions via increasing strength of the tropical Pacific trade winds and the resultant enhanced equatorial upwelling (Liu et al., 2000). Sensitivity experiments with fully coupled climate models demonstrate that greening of the Sahara during the mid-Holocene could reduce ENSO variability through affecting the Atlantic Niño (Zebiak, 1993) and Walker circulation, finally decreasing upwelling and deepening of the thermocline in the eastern Pa- 

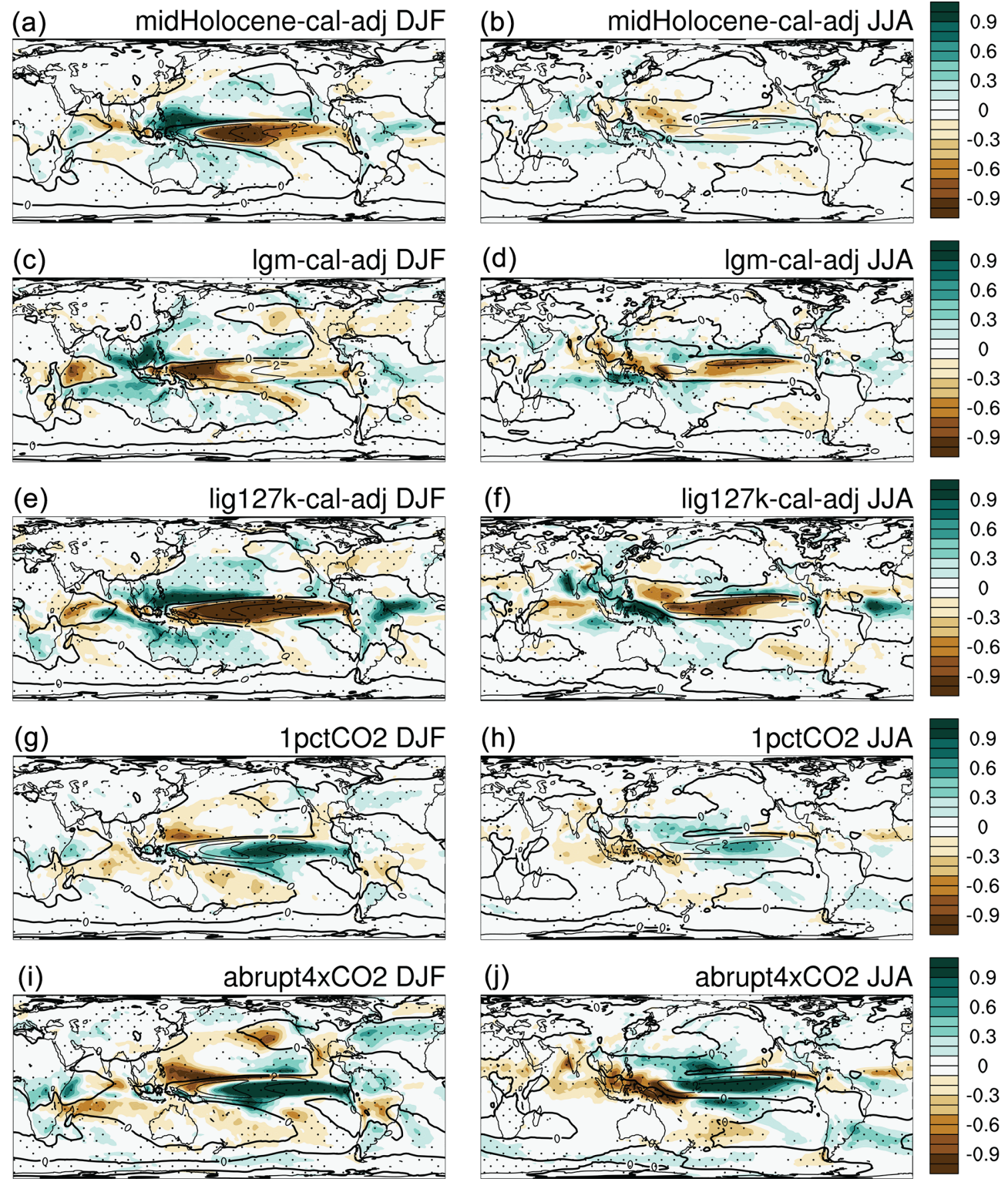

Figure 12. The changes in the seasonal precipitation teleconnection pattern associated with ENSO in each experiment compared with the pre-industrial control. The ensemble mean difference between the precipitation composites of each model's El Niño minus La Niña (defined as \pm 1 standard deviation) in the $(\mathbf{a}, \mathbf{b})$ midHolocene, $(\mathbf{c}, \mathbf{d}) \operatorname{lgm},(\mathbf{e}, \mathbf{f}) \operatorname{lig} 127 \mathrm{k},(\mathbf{g}, \mathbf{h}) 1 \mathrm{pctCO}$, and $(\mathbf{i}, \mathbf{j})$ abrupt4xCO2 experiments minus the same pattern for the piControl simulations is shown. The ensemble mean ENSO patterns in the piControl simulations are shown as black contours. Stippling indicates that more than two-thirds of the ensemble members agree on the sign of the change.

cific (Pausata et al., 2017). The freshwater perturbation experiments, so-called "water hosing experiment" that lead to a weakening of the Atlantic Ocean meridional overturning circulation, showed a reduced seasonal cycle and enhanced ENSO variability through the inter-basin atmospheric teleconnection (Braconnot et al., 2012; Masson-Delmotte et al., 2014; Timmermann et al., 2007).

More sophisticated feedback analysis revealed that the reduction of ENSO variability is due to either the increase of the negative feedback by the mean current thermal advec- tion (An and Bong, 2018) or the reduction of the major positive feedback processes (thermocline, zonal advection and Ekman feedbacks) (Chen et al., 2019a; Tian et al., 2017). The negative feedback due to the thermal advection by the mean current was intensified by the stronger cross-equatorial winds associated with the northward migration of the ITCZ (e.g. An and Choi, 2014), and the positive dynamical feedback was suppressed due to the strengthening of the mean $\mathrm{Pa}$ cific subtropical cell (Chen et al., 2019a). Therefore, the linear stability of ENSO during the mid-Holocene was reduced 

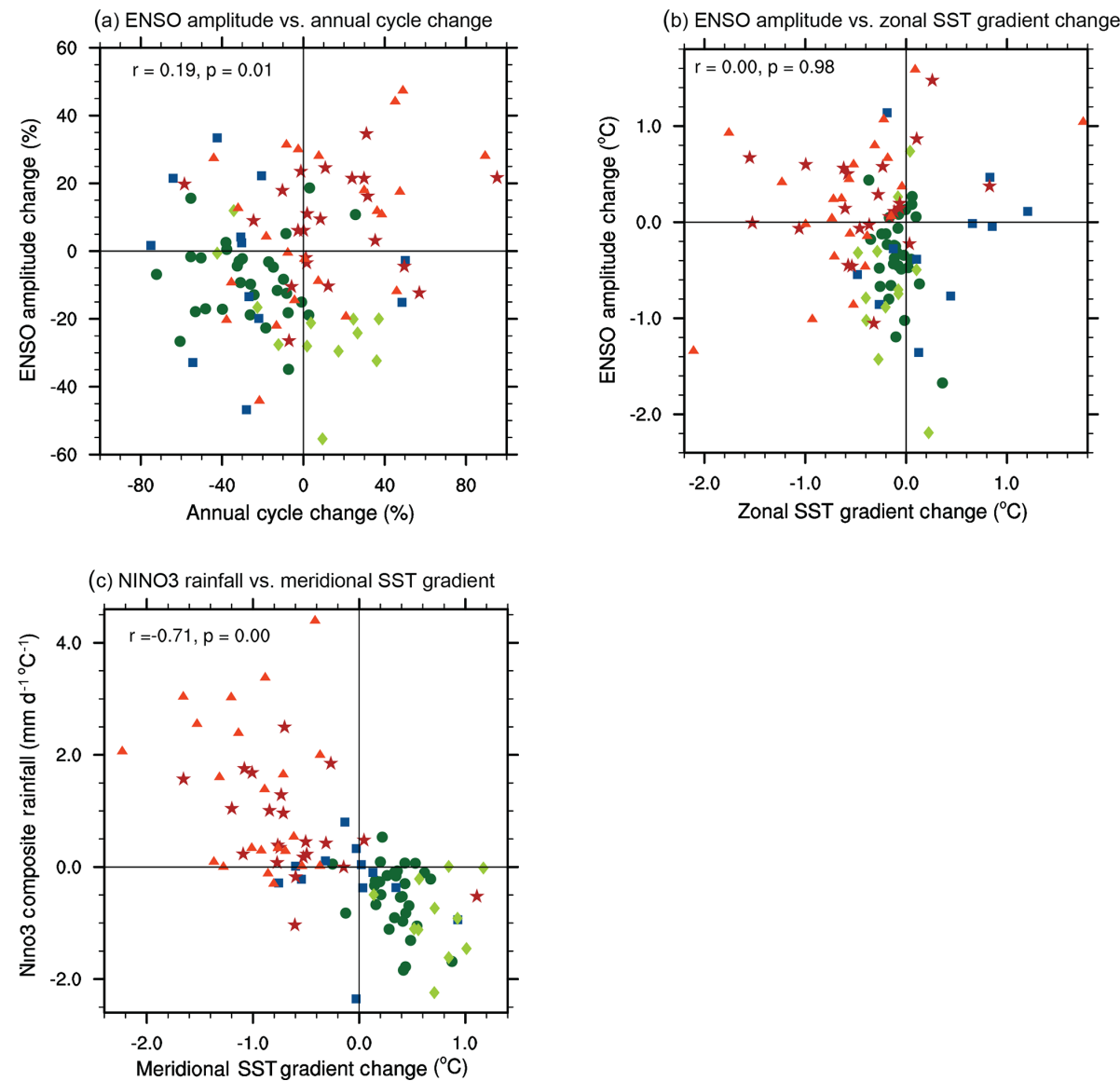

Figure 13. Relationships across all experiments and all models: (a) ENSO amplitude change (\%) versus change in the annual cycle (\%), (b) ENSO amplitude change $\left({ }^{\circ} \mathrm{C}\right)$ versus zonal SST gradient change $\left({ }^{\circ} \mathrm{C}\right)$, and (c) NINO3 precipitation for ENSO composite versus meridional SST gradient change $\left({ }^{\circ} \mathrm{C}\right)$. All changes are relative to piControl; see text for details. Experiments are identified as follows: blue squares indicate $l g m$, dark green circles indicate midHolocene, light green diamonds indicate lig $127 \mathrm{k}$, dark red stars indicate $1 p c t C O 2$, and light red triangles indicate abrupt $4 x \mathrm{CO} 2$ (after bar charts in Fig. 8). Correlation coefficients are shown for each plot.

through the dedicated balance among the various feedback processes, but the change in each feedback process is model dependent. External processes were also proposed as a suppression mechanism for mid-Holocene ENSO. For example, the Pacific meridional mode became weaker during the midHolocene; thereby, ENSO has a relatively lower chance of being triggered (Chiang et al., 2009); the weaker ocean stratification due to the warm water subduction from the subtropical ocean decreases ENSO stability (Liu et al., 2000).

How ENSO activity will change in response to anthropogenic global warming still remains uncertain (Cai et al., 2015a; Christensen et al., 2014; Collins et al., 2010). Observations show that ENSO variability has increased under greenhouse warming in the recent past (Zhang et al., 2008), which is also shown in CMIP5 climate model simulations (Cai et al., 2018). During the transient period of global warming, the tropical SSTs warm much faster than the subsurface ocean and leads to a shallower and stronger thermocline in the equatorial Pacific (An et al., 2008), which enhances the ocean-atmosphere coupling and amplifies the ENSO variability (Zhang et al., 2008). A gradually intensified ENSO from the mid-Holocene to late Holocene also appears in a long-transient simulation since the last 21000 years (Liu et al., 2014) and of the last 6000 years (Braconnot et al., 2019). For the equilibrium response to global warming, the subsurface ocean will eventually warm up and reduce the vertical temperature gradient and weaken the ENSO variability. For instance, during the Pliocene warm period, the most recent period in the past with carbon dioxide concentrations similar or higher than today, SST reconstructions from the tropical Pacific show a reduced zonal SST gradient during this period, implying sustained El Niño-like conditions (Dekens et al., 2007; Fedorov et al., 2006; Wara et al., 2005) as well as a deeper thermocline with weaker thermocline feedback (White and Ravelo, 2020).

It is still a topic of debate as to whether the tropical climate mean state response to current global warming will be El Niño-like or La Niña-like (Cane et al., 1997; Collins, 2005; 
Merryfield 2006; An et al., 2012; Collins et al., 2010; Lian et al., 2018). Moreover, the global warming-induced tropical Pacific SST pattern seems to be less effective in changing ENSO activity (An and Choi, 2015). The strong internal modulation of ENSO activity over decadal-to-centennial timescales also obscures the actual global warming impact on ENSO variability (e.g. Wittenberg, 2009). So far, the future ENSO activity reflected in SST anomalies obtained from CMIP5 models is not distinguishable from the historical ENSO activity (Christensen et al., 2014).

The enhancement and increasingly frequent occurrence of ENSO-driven extreme atmospheric responses to future global warming are strongly supported by model studies. This includes extreme rainfall events and extreme equatorward swings of the SPCZ (Cai et al., 2014, 2015a, 2012) and extreme weather events through teleconnections (Cai et al., 2015a; Yeh et al., 2018). The changes in these extremes are due to the nonlinearity of atmospheric response to ENSO SSTs, especially with a warmer ocean surface. The changing amplitude of the extremes with changing meridional SST gradient is a feature of past climates as well as future climates. This is demonstrated in Fig. 13c, which shows an increase in the ENSO composited precipitation with increased SST gradient. However, most current GCMs still inaccurately simulate many aspects of the historical ENSO such as the far westward extent of the Pacific cold tongue (Taschetto et al., 2014), ENSO-related precipitation anomalies (Dai and Arkin, 2017), ENSO feedbacks (Bayr et al., 2019; Bellenger et al., 2014; Kim et al., 2014; Kim and Jin, 2011; Lloyd et al., 2012), and ENSO asymmetry in amplitude, duration, and transition (e.g. Chen et al., 2017; Zhang and Sun, 2014). Therefore, the accuracy of the future projections of ENSO will be guaranteed only when most coupled GCMs can simulate the observed modern-day ENSO more skilfully than they can at present.

\section{Summary and conclusions}

We have presented a summary of ENSO amplitude and teleconnections changes in the most recent previous generation (CMIP5) and the new generation (CMIP6) of coupled climate models for past and future climates. The analysed simulations include the Last Glacial Maximum climate (lgm), past interglacial climates (lig127k and midHolocene), and future idealised projections (abrupt $4 x \mathrm{CO} 2$ and 1 pctCO2), using the pre-industrial climate (piControl) as the reference state.

We first evaluated a 30-year climatology from the historical simulation against HadISST observation from 1971 to 2000. Similarly to the previous generations of climate models, the CMIP5 and CMIP6 models have cold biases in SST in the central to western equatorial Pacific, as well as in the subtropical Pacific. Warm SST biases are present in the eastern equatorial Pacific. The piControl climate is about $1{ }^{\circ} \mathrm{C}$ colder on average than the historical climate, leading to an apparent exacerbation of the cold-tongue bias and reduction in the warm bias in the eastern equatorial Pacific. These biases in SST lead to a strong and northward shift of ITCZ, a dry bias along the equatorial Pacific, and appearance of a "double ITCZ" as in previous CMIP-class simulations. SST and precipitation biases are generally slightly smaller in the new generation of CMIP6 models than in the CMIP5 models. The simulated ENSO pattern well resembles the observations with a slight displacement to the west; similarly, the ENSO temperature and precipitation teleconnections are well simulated compared with observations.

The mean state changes were examined relative to the $p i$ Control simulation. In the lig $127 k$ simulations, strong seasonal insolation anomalies lead to tropical and subtropical SST cooling of $0.5-2{ }^{\circ} \mathrm{C}$ in DJF and JJA. No large-scale warming is found in the midHolocene simulations, but a slight cooling of $0.5^{\circ} \mathrm{C}$ occurs in the eastern Pacific in DJF and in the central Pacific in JJA. In the lgm simulations, $2-3{ }^{\circ} \mathrm{C}$ cooling is found in the tropical Pacific. For the future scenarios, the tropical Pacific warms by $1-3^{\circ} \mathrm{C}$ in the IpctCO2 case and more than $3{ }^{\circ} \mathrm{C}$ in the abrupt $4 x \mathrm{CO} 2$ case. During the lig $127 k$ and midHolocene simulations, the ITCZ shifts northward, leading to a weakened Australian summer monsoon and enhanced North American summer monsoon. In the lgm simulations, the ITCZ is intensified over the tropical Pacific, with drier conditions over the Maritime Continent, Australia, and southeast Asia, while wetter conditions are found in the western Pacific and on the northern edge of the SPCZ. In the 1pctCO2 and abrupt4xCO2 simulations, precipitation increases in the equatorial Pacific following the largest SST warming, with some drying on the northern edge of the ITCZ and in southeast Pacific in DJF.

The majority of models show a decrease in ENSO variability in the lig127k and midHolocene simulations. The reduction of ENSO variability in lig $127 \mathrm{k}$ ranges to more than $40 \%$, while only one model shows more than a $\sim 20 \%$ decrease in ENSO variability in midHolocene. This is consistent with previous model studies of mid-Holocene ENSO, which generally show a smaller reduction in amplitude than implied by proxy records.

The changes in ENSO variability in lgm, $1 p c t C O 2$ and abrupt $4 x \mathrm{CO} 2$ simulations are highly model dependent, with the sign of change approximately equally divided between increases and decreases of up to $40 \%$ to $50 \%$ across the set of models. This is also consistent with previous studies showing little agreement on ENSO amplitude change under LGM conditions (Masson-Delmotte et al., 2014) or in future projections (Collins et al., 2014).

The ensemble mean weakening of ENSO in the lgm simulations is characterised by a cooling in the central and western Pacific. Cooling over Australia and warming over North America are also evident. The changes in the ENSO temperature teleconnections show cooling in the central Pacific in lig127k and midHolocene, and significant global warming in the abrupt4xCO2 simulation, with strong warming am- 
plification over continents and high northern latitudes. The lpctCO2 simulations show a similar warming pattern but with much weaker magnitude. Precipitation teleconnections follow the change in ensemble mean ENSO amplitude, with a weakening of the climatological piControl ENSO precipitation response in the lgm, lig $127 \mathrm{k}$, and midHolocene cases. In the lgm simulations, a weaker hydrological cycle due to cooler temperatures may also play a role. The precipitation response to ENSO is significant in the abrupt4xCO2 and 1pctCO2 simulations, with an amplification of the climatological ENSO teleconnection pattern. This is consistent with previous studies showing increased ENSO precipitation responses in a warmer climate.

This study has provided an overview of changes in the mean state and ENSO in a set of past and future climate simulations from PMIP3/CMIP5 and PMIP4/CMIP6 models. We have not provided a comprehensive analysis of any aspect of these changes, and the set of CMIP6 models included is necessarily incomplete. Future work will focus on deepening understanding of the complex mechanisms driving interactions between changes in the mean state and ENSO. A more detailed comparison with palaeo-ENSO proxy records will also be required to evaluate model simulations of ENSO in past climates (e.g. Lu et al., 2018). Improved understanding of changes in ENSO in past climates can contribute to model evaluation, understanding of ENSO dynamics, and constraining projections of future change.

Code and data availability. The CMIP5 and CMIP6 model data used in this study are available from the Earth System Grid Federation. All the processed model output and scripts to produce the figures in this study are provided on the GitHub repository: https: //github.com/chrisbrierley/PMIP4-enso (last access: 8 July 2020; chrisbrierley, 2020).

Supplement. The supplement related to this article is available online at: https://doi.org/10.5194/cp-16-1777-2020-supplement.

Author contributions. JRB coordinated the research. CMB performed the simulation analysis. JRB, CMB, S-IA, M-VG, SS, CJRW, QZ, and AZ authored the manuscript with edits from RD. Other authors contributed simulations towards the analysis.

Competing interests. The authors declare that they have no conflict of interest.

Special issue statement. This article is part of the special issue "Paleoclimate Modelling Intercomparison Project phase 4 (PMIP4) (CP/GMD inter-journal SI)". It is not associated with a conference.
Acknowledgements. Josephine R. Brown acknowledges support from the ARC Centre of Excellence for Climate Extremes (CE170100023). Chris M. Brierley, Charles J. R. Williams, Pascale Braconnot, Roberta D'Agostino, Gerrit Lohmann, and Xiaoxu Shi acknowledge the JPI-Belmont-funded PACMEDY programme (NE/P006752/1; ANR-15-JCLI-0003-01; BMBF 01LP1607A). Soon-Il An was supported by the National Research Foundation of Korea (NRF) grant (NRF-2018R1A5A1024958). Chris M. Brierley was also funded in part by NERC (NE/S009736/1). Maria-Vittoria Guarino acknowledges support from NERC research grant NE/P013279/1. Qiong Zhang acknowledges support from the Swedish Research Council VR projects 2013-06476 and 201704232. The EC-Earth simulations are performed on resources provided by the Swedish National Infrastructure for Computing (SNIC) at the National Supercomputer Centre (NSC), partially funded by the Swedish Research Council through grant no. 2016-07213. Rumi Ohgaito acknowledges support from the Integrated Research Program for Advancing Climate Models (TOUGOU programme) from the Ministry of Education, Culture, Sports, Science and Technology (MEXT), Japan. The simulations using MIROC-ES2L were conducted on the Earth Simulator of JAMSTEC. Ryouta O'ishi and Ayako Abe-Ouchi acknowledge support from Arctic Challenge for Sustainability (ArCS) project (grant no. JPMXD1300000000), JSPS KAKENHI (grant no. 17H06104) and MEXT KAKENHI (grant no. 17H06323), and JAMSTEC for use of the Earth Simulator supercomputer. Bette L. Otto-Bliesner and Esther C. Brady acknowledge the CESM project, supported primarily by the $\mathrm{Na}$ tional Science Foundation (NSF). The CESM2 simulations are based upon work supported by the National Center for Atmospheric Research (NCAR), which is a major facility sponsored by the NSF under cooperative agreement no. 1852977. Computing and data storage resources, including the Cheyenne supercomputer (https://doi.org/10.5065/D6RX99HX), were provided by the Computational and Information Systems Laboratory (CISL) at NCAR. Polina A. Morozova was supported by state assignment project 0148-2019-0009. Evgeny M. Volodin was supported by RSF grant no. 20-17-00190. We acknowledge the World Climate Research Programme, which, through its Working Group on Coupled Modelling, coordinated and promoted CMIP6. We thank the climate modelling groups for producing and making available their model output, the Earth System Grid Federation (ESGF) for archiving the data and providing access, and the multiple funding agencies who support CMIP6 and ESGF. PMIP is endorsed by both WCRP/WGCM and Future Earth/PAGES. This research arose out of a workshop hosted at University College London by the PMIP working group on Past2Future: insights from a constantly varying past.

Financial support. This research has been supported by the JPI-Belmont-funded PACMEDY programme (grant nos. NE/P006752/1, ANR-15-JCLI-0003-01, and BMBF 01LP1607A); the National Research Foundation of Korea (grant no. NRF2018R1A5A1024958); the UK NERC (grant nos. NE/S009736/1 and NE/P013279/1); the Swedish Research Council (VR projects 2013-06476, 2017-04232, and 2016-07213); the Integrated Research Program for Advancing Climate Models (TOUGOU programme) from the Ministry of Education, Culture, Sports, Science and Technology (MEXT), Japan; the Arctic Challenge 
for Sustainability (ArCS) project (grant no. JPMXD1300000000), JSPS KAKENHI (grant no. 17H06104) and MEXT KAKENHI (grant no. 17H06323); the US National Science Foundation (NSF) under cooperative agreement no. 1852977; the Russian State Assignment Project 0148-2019-0009; and the Russian Science Foundation (RSF) (grant no. 20-17-00190).

Review statement. This paper was edited by Julien Emile-Geay and reviewed by three anonymous referees.

\section{References}

Abe-Ouchi, A., Saito, F., Kageyama, M., Braconnot, P., Harrison, S. P., Lambeck, K., Otto-Bliesner, B. L., Peltier, W. R., Tarasov, L., Peterschmitt, J.-Y., and Takahashi, K.: Ice-sheet configuration in the CMIP5/PMIP3 Last Glacial Maximum experiments, Geosci. Model Dev., 8, 3621-3637, https://doi.org/10.5194/gmd-8-36212015, 2015.

Adam, O., Schneider, T., and Brient, F.: Regional and seasonal variations of the double-ITCZ bias in CMIP5 models, Clim. Dynam., 51, 101-117, 2018.

Adler, R. F., Huffman, G. J., Chang, A., Ferraro, R., Xie, P. P., Janowiak, J., Rudolf, B., Schneider, U., Curtis, S., Bolvin, D., Gruber, A., Susskind, J., Arkin, P., and Nelkin, E.: The version2 global precipitation climatology project (GPCP) monthly precipitation analysis (1979-present), J. Hydrometeorol., 4, 11471167, 2003.

An, S. I. and Bong, H.: Feedback process responsible for the suppression of ENSO activity during the mid-Holocene, Theor. Appl. Climatol., 132, 779-790, 2018.

An, S.-I. and Choi, J.: Inverse relationship between the equatorial eastern Pacific annual-cycle and ENSO amplitudes in a coupled general circulation model, Clim. Dynam., 40, 663-675, 2013.

An, S. I. and Choi, J.: Mid-Holocene tropical Pacific climate state, annual cycle, and ENSO in PMIP2 and PMIP3, Clim. Dynam., 43, 957-970, 2014.

An, S. I. and Choi, J.: Why the twenty-first century tropical Pacific trend pattern cannot significantly influence ENSO amplitude?, Clim. Dynam., 44, 133-146, 2015.

An, S. I. and Jin, F. F.: Nonlinearity and asymmetry of ENSO, J. Climate, 17, 2399-2412, 2004.

An, S. I. and Kim, J. W.: Role of nonlinear ocean dynamic response to wind on the asymmetrical transition of El Nino and La Nina, Geophys. Res. Lett., 44, 393-400, 2017.

An, S. I. and Kim, J. W.: ENSO Transition Asymmetry: Internal and External Causes and Intermodel Diversity, Geophys. Res. Lett., 45, 5095-5104, 2018.

An, S. I., Kug, J. S., Ham, Y. G., and Kang, I. S.: Successive modulation of ENSO to the future greenhouse warming, J. Climate, 21, 3-21, 2008.

An, S.-I., Ham, Y.-G., Kug, J.-S., Timmermann, A., Choi, J., and Kang, I.-S.: The Inverse Effect of Annual-Mean State and Annual-Cycle Changes on ENSO, J. Climate, 23, 1095-1110, 2010.

An, S. I., Kim, J. W., Im, S. H., Kim, B. M., and Park, J. H.: Recent and future sea surface temperature trends in tropical pacific warm pool and cold tongue regions, Clim. Dynam., 39, 13731383, 2012.

An, S.-I., Kim, H.-J., Park, W., and Schneider, B.: Impact of ENSO on East Asian winter monsoon during interglacial periods: effect of orbital forcing, Clim. Dynam., 49, 3209-3219, 2017.

An, S. I., Im, S. H., and Jun, S. Y.: Changes in ENSO Activity During the Last 6,000 Years Modulated by Background Climate State, Geophys. Res. Lett., 45, 2467-2475, 2018.

Andrews, T., Gregory, J. M., Webb, M. J., and Taylor, K. E.: Forcing, feedbacks and climate sensitivity in CMIP5 coupled atmosphere-ocean climate models, Geophys. Res. Lett., 39, L09712, https://doi.org/10.1029/2012GL051607, 2012.

Ashok, K., Behera, S. K., Rao, S. A., Weng, H. Y., and Yamagata, T.: El Nino Modoki and its possible teleconnection, J. Geophys. Res.-Oceans, 112, C11007, https://doi.org/10.1029/2006JC003798, 2007.

Ballantyne, A., Lavine, M., Crowley, T., Liu, J., and Baker, P.: Meta-analysis of tropical surface temperatures during the Last Glacial Maximum, Geophys. Res. Lett., 32, L05712, https://doi.org/10.1029/2004GL021217, 2005.

Barr, C., Tibby, J., Leng, M. J., Tyler, J. J., Henderson, A. C. G., Overpeck, J. T., Simpson, G. L., Cole, J. E., Phipps, S. J., Marshall, J. C., McGregor, G. B., Hua, Q., and McRobie, F. H.: Holocene El Niño-Southern Oscillation variability reflected in subtropical Australian precipitation, Sci. Rep., 9, 1-9, 2019.

Bartlein, P. J. and Shafer, S. L.: Paleo calendar-effect adjustments in time-slice and transient climate-model simulations (PaleoCalAdjust v1.0): impact and strategies for data analysis, Geosci. Model Dev., 12, 3889-3913, https://doi.org/10.5194/gmd-123889-2019, 2019.

Bayr, T. and Dommenget, D.: The tropospheric land-sea warming contrast as the driver of tropical sea level pressure changes, J. Climate, 26, 1387-1402, 2013.

Bayr, T., Dommenget, D., Martin, T., and Power, S.B.: The eastward shift of the Walker Circulation in response to global warming and its relationship to ENSO variability, Clim. Dynam., 43, 27472763, 2014.

Bayr, T., Latif, M., Dommenget, D., Wengel, C., Harlass, J. and Park, W.: Mean-state dependence of ENSO atmospheric feedbacks in climate models, Clim. Dynam., 50, 3171-3194, 2018.

Bayr, T., Wengel, C., Latif, M., Dommenget, D., Lubbecke, J., and Park, W.: Error compensation of ENSO atmospheric feedbacks in climate models and its influence on simulated ENSO dynamics, Clim. Dynam., 53, 155-172, 2019.

Bellenger, H., Guilyardi, E., Leloup, J., Lengaigne, M., and Vialard, J.: ENSO representation in climate models: from CMIP3 to CMIP5, Clim. Dynam., 42, 1999-2018, 2014.

Berger, A. and Loutre, M. F.: Insolation Values for the Climate of the Last 10000000 Years, Quaternary Sci. Rev., 10, 297-317, 1991.

Braconnot, P., Otto-Bliesner, B., Harrison, S., Joussaume, S., Peterchmitt, J.-Y., Abe-Ouchi, A., Crucifix, M., Driesschaert, E., Fichefet, Th., Hewitt, C. D., Kageyama, M., Kitoh, A., Loutre, M.-F., Marti, O., Merkel, U., Ramstein, G., Valdes, P., Weber, L., Yu, Y., and Zhao, Y.: Results of PMIP2 coupled simulations of the Mid-Holocene and Last Glacial Maximum - Part 2: feedbacks with emphasis on the location of the ITCZ and mid- and high latitudes heat budget, Clim. Past, 3, 279-296, https://doi.org/10.5194/cp-3-279-2007, 2007. 
Braconnot, P., Harrison, S. P., Kageyama, M., Bartlein, P. J., Masson-Delmotte, V., Abe-Ouchi, A., Otto-Bliesner, B., and Zhao, Y.: Evaluation of climate models using palaeoclimatic data, Nat. Clim. Change, 2, 417-424, 2012.

Braconnot, P., Crétat, J., Marti, O., Balkanski, Y., Caubel, A., Cozic, A., Foujols, M.-A., and Sanogo, S.: Impact of Multiscale Variability on Last 6,000 Years Indian and West African Monsoon Rain, Geophys. Res. Lett., 46, 14021-14029, https://doi.org/doi.org/10.1029/2019GL084797, 2019.

Brierley, C.: ENSO behavior before the Pleistocene, PAGES news, 21, 70-71, 2013.

Brierley, C. and Wainer, I.: Inter-annual variability in the tropical Atlantic from the Last Glacial Maximum into future climate projections simulated by CMIP5/PMIP3, Clim. Past, 14, 13771390, https://doi.org/10.5194/cp-14-1377-2018, 2018.

Brierley, C. M., Fedorov, A. V., Liu, Z. H., Herbert, T. D., Lawrence, K. T., and LaRiviere, J. P.: Greatly Expanded Tropical Warm Pool and Weakened Hadley Circulation in the Early Pliocene, Science, 323, 1714-1718, 2009.

Brierley, C. M., Zhao, A., Harrison, S. P., Braconnot, P., Williams, C. J. R., Thornalley, D. J. R., Shi, X., Peterschmitt, J.-Y., Ohgaito, R., Kaufman, D. S., Kageyama, M., Hargreaves, J. C., Erb, M. P., Emile-Geay, J., D’Agostino, R., Chandan, D., Carré, M., Bartlein, P., Zheng, W., Zhang, Z., Zhang, Q., Yang, H., Volodin, E. M., Tomas, R. A., Routson, C., Peltier, W. R., OttoBliesner, B., Morozova, P. A., McKay, N. P., Lohmann, G., Legrande, A. N., Guo, C., Cao, J., Brady, E., Annan, J. D., and Abe-Ouchi, A.: Large-scale features and evaluation of the PMIP4-CMIP6 midHolocene simulations, Clim. Past Discuss., https://doi.org/10.5194/cp-2019-168, in review, 2020.

Brown, J. R., Moise, A. F., and Colman, R. A.: The South Pacific Convergence Zone in CMIP5 simulations of historical and future climate, Clim. Dynam., 41, 2179-2197, 2013.

Brown, J. R., Hope, P., Gergis, J., and Henley, B. J.: ENSO teleconnections with Australian rainfall in coupled model simulations of the last millennium, Clim. Dynam., 47, 79-93, 2016.

Burls, N. J. and Fedorov, A. V.: Simulating Pliocene warmth and a permanent El Nino-like state: The role of cloud albedo, Paleoceanography, 29, 893-910, 2014.

Cai, W. J., Lengaigne, M., Borlace, S., Collins, M., Cowan, T., McPhaden, M. J., Timmermann, A., Power, S., Brown, J., Menkes, C., Ngari, A., Vincent, E. M., and Widlansky, M. J.: More extreme swings of the South Pacific convergence zone due to greenhouse warming, Nature, 488, 365-369, 2012.

Cai, W., Borlace, S., Lengaigne, M., van Rensch, P., Collins, M., Vecchi, G., Timmermann, A., Santoso, A., McPhaden, M. J., Wu, L., England, M. H., Wang, G., Guilyardi, E., and Jin, F.-F.: Increasing frequency of extreme El Niño events due to greenhouse warming, Nat. Clim. Change, 4, 111-116, 2014.

Cai, W., Santoso, A., Wang, G., Yeh, S.-W., An, S.-I., Cobb, K. M., Collins, M., Guilyardi, E., Jin, F.-F., Kug, J.-S., Lengaigne, M., McPhaden, M. J., Takahashi, K., Timmermann, A., Vecchi, G., Watanabe, M., and Wu, L.: ENSO and greenhouse warming, Nat. Clim. Change, 5, 849-859, 2015a.

Cai, W. J., Wang, G. J., Santoso, A., McPhaden, M. J., Wu, L. X., Jin, F. F., Timmermann, A., Collins, M., Vecchi, G., Lengaigne, M., England, M. H., Dommenget, D., Takahashi, K., and Guilyardi, E.: Increased frequency of extreme La Nina events under greenhouse warming, Nat. Clim. Change, 5, 132-137, $2015 \mathrm{~b}$.
Cai, W. J., Wang, G. J., Dewitte, B., Wu, L. X., Santoso, A., Takahashi, K., Yang, Y., Carreric, A., and McPhaden, M. J.: Increased variability of eastern Pacific El Nino under greenhouse warming, Nature, 564, 201-206, 2018.

Cane, M. A., Clement, A. C., Kaplan, A., Kushnir, Y., Pozdnyakov, D., Seager, R., Zebiak, S. E., and Murtugudde, R.: Twentiethcentury sea surface temperature trends, Science, 275, 957-960, 1997.

Capotondi, A., Wittenberg, A. T., Newman, M., Di Lorenzo, E., Yu, J. Y., Braconnot, P., Cole, J., Dewitte, B., Giese, B., Guilyardi, E., Jin, F. F., Karnauskas, K., Kirtman, B., Lee, T., Schneider, N., Xue, Y., and Yeh, S. W.: Understanding ENSO Diversity, B. Am. Meteorol. Soc., 96, 921-938, 2015.

Carré, M., Sachs, J. P., Purea, S., Schauer, A. J., Braconnot, P., Falcom, R. A., Julien, M., and Lavallee, D.: Holocene history of ENSO variance and asymmetry in the eastern tropical Pacific, Science, 345, 1045-1048, 2014.

Ceppi, P., Brient, F., Zelinka, M. D., and Hartmann, D. L.: Cloud feedback mechanisms and their representation in global climate models, Wires Clim. Change, 8, e465, 2017.

Chadwick, R., Boutle, I., and Martin, G.: Spatial patterns of precipitation change in CMIP5: Why the rich do not get richer in the tropics, J. Climate, 26, 3803-3822, 2013.

Chaisson, W. P. and Ravelo, A. C.: Pliocene development of the east-west hydrographic gradient in the equatorial Pacific, Paleoceanography, 15, 497-505, 2000.

Chen, L., Li, T., Yu, Y. Q., and Behera, S. K.: A possible explanation for the divergent projection of ENSO amplitude change under global warming, Clim. Dynam., 49, 3799-3811, 2017.

Chen, L., Wang, L., Li, T., and Liu, J.: Drivers of reduced ENSO variability in mid-Holocene in a coupled model, Clim. Dynam., 52, 5999-6014, 2019a.

Chen, L., Zheng, W. P., and Braconnot, P.: Towards understanding the suppressed ENSO activity during mid-Holocene in PMIP2 and PMIP3 simulations, Clim. Dynam., 53, 1095-1110, 2019b.

Chiang, J. C. H., Fang, Y., and Chang, P.: Pacific Climate Change and ENSO Activity in the Mid-Holocene, J. Climate, 22, 923939, 2009.

chrisbrierley: PMIP4-enso, GitHub, available at: https://github. com/chrisbrierley/PMIP4-enso, GitHub, last access: 8 July 2020.

Christensen, J. H., Kanikicharla, K. K., Aldrian, E., An, S. I., Cavalcanti, I. F. A., de Castro, M., Dong, W. J., Goswami, P., Hall, A., Kanyanga, J. K., Kitoh, A., Kossin, J., Lau, N. C., Renwick, J., Stephenson, D. B., Xie, S. P., Zhou, T. J., Abraham, L., Ambrizzi, T., Anderson, B., Arakawa, O., Arritt, R., Baldwin, M., Barlow, M., Barriopedro, D., Biasutti, M., Biner, S., Bromwich, D., Brown, J., Cai, W. J., Carvalho, L. V., Chang, P., Chen, X. L., Choi, J., Christensen, O. B., Deser, C., Emanuel, K., Endo, H., Enfield, D. B., Evan, A., Giannini, A., Gillett, N., Hariharasubramanian, A., Huang, P., Jones, J., Karumuri, A., Katzfey, J., Kjellstrom, E., Knight, J., Knutson, T., Kulkarni, A., Kundeti, K. R., Lau, W. K., Lenderink, G., Lennard, C., Leung, L. Y. R., Lin, R. P., Losada, T., Mackellar, N. C., Magana, V., Marshall, G., Mearns, L., Meehl, G., Menendez, C., Murakami, H., Nath, M. J., Neelin, J. D., van Oldenborgh, G. J., Olesen, M., Polcher, J., Qian, Y., Ray, S., Reich, K. D., de Fonseca, B. R., Ruti, P., Screen, J., Sedlacek, J., Solman, S., Stendel, M., Stevenson, S., Takayabu, I., Turner, J., Ummenhofer, C., Walsh, K., Wang, B., Wang, C. Z., Watterson, I., Widlansky, M., Wittenberg, 
A., Woollings, T., Yeh, S. W., Zhang, C. D., Zhang, L. X., Zheng, X. T., and Zou, L. W.: Climate Phenomena and their Relevance for Future Regional Climate Change, Climate Change 2013: The Physical Science Basis, 1217-1308, 2014.

Clement, A. C., Seager, R., and Cane, M. A.: Suppression of El Nino during the mid-Holocene by changes in the Earth's orbit, Paleoceanography, 15, 731-737, 2000.

Cobb, K. M., Charles, C. D., Cheng, H., and Edwards, R. L.: El Nino/Southern Oscillation and tropical Pacific climate during the last millennium, Nature, 424, 271-276, 2003.

Cobb, K. M., Westphal, N., Sayani, H. R., Watson, J. T., Di Lorenzo, E., Cheng, H., Edwards, R. L., and Charles, C. D.: Highly Variable El Nino-Southern Oscillation Throughout the Holocene, Science, 339, 67-70, 2013.

Collins, M.: Understanding uncertainties in the response of ENSO to greenhouse warming, Geophys. Res. Lett., 27, 3509-3512, 2000.

Collins, M.: El Nino- or La Nina-like climate change?, Clim. Dynam., 24, 89-104, 2005.

Collins, M., An, S. I., Cai, W. J., Ganachaud, A., Guilyardi, E., Jin, F. F., Jochum, M., Lengaigne, M., Power, S., Timmermann, A., Vecchi, G., and Wittenberg, A.: The impact of global warming on the tropical Pacific ocean and El Nino, Nat. Geosci., 3, 391-397, 2010.

Collins, M., Knutti, R., Arblaster, J., Dufresne, J. L., Fichefet, T., Friedlingstein, P., Gao, X. J., Gutowski, W. J., Johns, T., Krinner, G., Shongwe, M., Tebaldi, C., Weaver, A. J., Wehner, M., Allen, M. R., Andrews, T., Beyerle, U., Bitz, C. M., Bony, S., Booth, B. B., Brooks, H. E., Brovkin, V., Browne, O., Brutel-Vuilmet, C., Cane, M., Chadwick, R., Cook, E., Cook, K. H., Eby, M., Fasullo, J., Fischer, E. M., Forest, C. E., Forster, P., Good, P., Goosse, H., Gregory, J. M., Hegerl, G. C., Hezel, P. J., Hodges, K. I., Holland, M. M., Huber, M., Huybrechts, P., Joshi, M., Kharin, V., Kushnir, Y., Lawrence, D. M., Lee, R. W., Liddicoat, S., Lucas, C., Lucht, W., Marotzke, J., Massonnet, F., Matthews, H. D., Meinshausen, M., Morice, C., Otto, A., Patricola, C. M., Philippon-Berthier, G., Prabhat, Rahmstorf, S., Riley, W. J., Rogelj, J., Saenko, O., Seager, R., Sedlacek, J., Shaffrey, L. C., Shindell, D., Sillmann, J., Slater, A., Stevens, B., Stott, P. A., Webb, R., Zappa, G., and Zickfeld, K.: Long-term Climate Change: Projections, Commitments and Irreversibility, Climate Change 2013: The Physical Science Basis, 1029-.1136, 2014.

Collins, M., Sutherland, M., Bouwer, L., Cheong, S.-M., Fro“licher, T., Jacot Des Combes, H., Koll Roxy, M., Losada, I., McInnes, K., Ratter, B., Rivera-Arriaga, E., Susanto, R. D., Swingedouw, D., and Tibig, L.: Extremes, Abrupt Changes and Managing Risk, in: IPCC Special Report on the Ocean and Cryosphere in a Changing Climate, edited by: Pörtner, H.-O., Roberts, D. C., Masson-Delmotte, V., Zhai, P., Tignor, M., Poloczanska, E., Mintenbeck, K.,Alegría, A., Nicolai, M., Okem, A., Petzold, J., Rama, B., and Weyer, N. M., in press, 2020.

Compo, G. P., Whitaker, J. S., Sardeshmukh, P. D., Matsui, N., Allan, R. J., Yin, X., Gleason, B. E., Vose, R. S., Rutledge, G., Bessemoulin, P., Bronnimann, S., Brunet, M., Crouthamel, R. I., Grant, A. N., Groisman, P. Y., Jones, P. D., Kruk, M. C., Kruger, A. C., Marshall, G. J., Maugeri, M., Mok, H. Y., Nordli, O., Ross, T. F., Trigo, R. M., Wang, X. L., Woodruff, S. D., and Worley, S. J.: The Twentieth Century Reanalysis Project, Q. J. Roy. Meteor. Soc., 137, 1-28, 2011.
Conroy, J. L., Overpeck, J. T., Cole, J. E., Shanahan, T. M., and Steinitz-Kannan, M.: Holocene changes in eastern tropical Pacific climate inferred from a Galápagos lake sediment record, Quaternary Sci. Rev., 27, 1166-1180, 2008.

Dai, N. and Arkin, P. A.: Twentieth century ENSO-related precipitation mean states in twentieth century reanalysis, reconstructed precipitation and CMIP5 models, Clim. Dynam., 48, 3061-3083, 2017.

Dekens, P. S., Ravelo, A. C., and McCarthy, M. D.: Warm upwelling regions in the Pliocene warm period, Paleoceanography, 22, PA3211, 2007.

Deser, C., Alexander, M. A., Xie, S. P., and Phillips, A. S.: Sea Surface Temperature Variability: Patterns and Mechanisms, Annu. Rev. Mar. Sci., 2, 115-143, 2010.

DiNezio, P. N., Clement, A. C., Vecchi, G. A., Soden, B. J., and Kirtman, B. P.: Climate Response of the Equatorial Pacific to Global Warming, J. Climate, 22, 4873-4892, 2009.

DiNezio, P. N., Timmermann, A., Tierney, J. E., Jin, F. F., OttoBliesner, B., Rosenbloom, N., Mapes, B., Neale, R., Ivanovic, R. F., and Montenegro, A.: The climate response of the Indo-Pacific warm pool to glacial sea level, Paleoceanography, 31, 866-894, 2016.

Donders, T. H., Wagner, F., Dilcher, D. L., and Visscher, H.: Mid- to late-Holocene El Nino-Southern Oscillation dynamics reflected in the subtropical terrestrial realm, P. Natl. Acad. Sci. USA, 102, 10904-10908, 2005.

Durack, P. J., Wijffels, S. E., and Matear, R. J.: Ocean Salinities Reveal Strong Global Water Cycle Intensification During 1950 to 2000, Science, 336, 455-458, 2012.

Eisenman, I., Yu, L. S., and Tziperman, E.: Westerly wind bursts: ENSO's tail rather than the dog?, J. Climate, 18, 5224-5238, 2005.

Emile-Geay, J., Cobb, K. M., Mann, M. E., and Wittenberg, A. T.: Estimating Central Equatorial Pacific SST Variability over the Past Millennium. Part II: Reconstructions and Implications, J. Climate, 26, 2329-2352, 2013.

Emile-Geay, J., Cobb, K. M., Carre, M., Braconnot, P., Leloup, J., Zhou, Y., Harrison, S. P., Correge, T., McGregor, H. V., Collins, M., Driscoll, R., Elliot, M., Schneider, B., and Tudhope, A.: Links between tropical Pacific seasonal, interannual and orbital variability during the Holocene, Nat. Geosci., 9, 168-173, 2016.

Eyring, V., Bony, S., Meehl, G. A., Senior, C. A., Stevens, B., Stouffer, R. J., and Taylor, K. E.: Overview of the Coupled Model Intercomparison Project Phase 6 (CMIP6) experimental design and organization, Geosci. Model Dev., 9, 1937-1958, https://doi.org/10.5194/gmd-9-1937-2016, 2016 a.

Eyring, V., Righi, M., Lauer, A., Evaldsson, M., Wenzel, S., Jones, C., Anav, A., Andrews, O., Cionni, I., Davin, E. L., Deser, C., Ehbrecht, C., Friedlingstein, P., Gleckler, P., Gottschaldt, K.D., Hagemann, S., Juckes, M., Kindermann, S., Krasting, J., Kunert, D., Levine, R., Loew, A., Mäkelä, J., Martin, G., Mason, E., Phillips, A. S., Read, S., Rio, C., Roehrig, R., Senftleben, D., Sterl, A., van Ulft, L. H., Walton, J., Wang, S., and Williams, K. D.: ESMValTool (v1.0) - a community diagnostic and performance metrics tool for routine evaluation of Earth system models in CMIP, Geosci. Model Dev., 9, 1747-1802, https://doi.org/10.5194/gmd-9-1747-2016, 2016 b.

Fedorov, A. V., Dekens, P. S., McCarthy, M., Ravelo, A. C., deMenocal, P. B., Barreiro, M., Pacanowski, R. C., and Philander, 
S. G.: The Pliocene paradox (mechanisms for a permanent El Nino), Science, 312, 1485-1489, 2006.

Fedorov, A. V., Brierley, C. M., Lawrence, K. T., Liu, Z., Dekens, P. S., and Ravelo, A. C.: Patterns and mechanisms of early Pliocene warmth, Nature, 496, 43-49, 2013.

Flato, G., Marotzke, J., Abiodun, B., Braconnot, P., Chou, S. C., Collins, W., Cox, P., Driouech, F., Emori, S., Eyring, V., Forest, C., Gleckler, P., Guilyardi, E., Jakob, C., Kattsov, V., Reason, C., Rummukainen, M., AchutaRao, K., Anav, A., Andrews, T., Baehr, J., Bindoff, N. L., Bodas-Salcedo, A., Catto, J., Chambers, D., Chang, P., Dai, A. G., Deser, C., Doblas-Reyes, F., Durack, P. J., Eby, M., de Elia, R., Fichefet, T., Forster, P., Frame, D., Fyfe, J., Gbobaniyi, E., Gillett, N., Gonzalez-Rouco, J. F., Goodess, C., Griffies, S., Hall, A., Harrison, S., Hense, A., Hunke, E., Ilyina, T., Ivanova, D., Johnson, G., Kageyama, M., Kharin, V., Klein, S. A., Knight, J., Knutti, R., Landerer, F., Lee, T., Li, H. M., Mahowald, N., Mears, C., Meehl, G., Morice, C., Msadek, R., Myhre, G., Neelin, J. D., Painter, J., Pavlova, T., Perlwitz, J., Peterschmitt, J. Y., Raisanen, J., Rauser, F., Reid, J., Rodwell, M., Santer, B., Scaife, A. A., Schulz, J., Scinocca, J., Sexton, D., Shindell, D., Shiogama, H., Sillmann, J., Simmons, A., Sperber, K., Stephenson, D., Stevens, B., Stott, P., Sutton, R., Thorne, P. W., van Oldenborgh, G. J., Vecchi, G., Webb, M., Williams, K., Woollings, T., Xie, S. P., and Zhang, J. L.: Evaluation of Climate Models, Climate Change 2013: The Physical Science Basis, 741866, 2014

Ford, H. L., Ravelo, A. C., and Polissar, P. J.: Reduced El NinoSouthern Oscillation during the Last Glacial Maximum, Science, 347, 255-258, 2015.

Ford, H. L., McChesney, C. L., Hertzberg, J. E., and McManus, J. F.: A deep eastern equatorial Pacific thermocline during the Last Glacial Maximum, Geophys. Res. Lett., 45, 11806-11816, 2018.

Freund, M. B., Henley, B. J., Karoly, D. J., McGregor, H. V., Abram, N. J., and Dommenget, D.: Higher frequency of Central Pacific El Nino events in recent decades relative to past centuries, Nat. Geosci., 12, 450-455, 2019.

Gagan, M. K. and Thompson, L. G.: Evolution of the IndoPacific warm pool and Hadley-Walker circulation since the last deglaciation, in: The Hadley circulation: present, past and future, Springer, 2004.

Gergis, J. L. and Fowler, A. M.: A history of ENSO events since AD 1525: implications for future climate change, Clim. Change, 92, 343-387, 2009.

Gregory, J. M., Ingram, W. J., Palmer, M. A., Jones, G. S., Stott, P. A., Thorpe, R. B., Lowe, J. A., Johns, T. C., and Williams, K. D.: A new method for diagnosing radiative forcing and climate sensitivity, Geophys. Res. Lett., 31, L03205, https://doi.org/10.1029/2003GL018747, 2004.

Grose, M. R., Narsey, S., Delage, F. P., Dowdy, A. J., Bador, M., Boschat, G., Chung, C., Kajtar, J. B., Rauniyar, S., Freund, M. B., Lyu, K., Rashid, H., Zhang, X., Wales, S., Trenham, C., Holbrook, N. J., Cowan, T., Alexander, L., Arblaster, J. M., and Power, S.:Insights from CMIP6 for Australia's future climate, Earth's Future, 8, e2019EF001469, https://doi.org/10.1029/2019EF001469, 2020.

Grothe, P. R., Cobb, K. M., Liguori, G., Di Lorenzo, E., Capotondi, A., Lu, Y., Cheng, H., Edwards, R.L., Southon, J. R., Santos, G. M., Deocampo, D. M., Lynch-Stieglitz, J., Chen, T., Sayani, H. R., Thompson, D. M., Conroy, J. L., Moore,
A. L., Townsend, K., Hagos, M., O'Connor, G., and Toth, L. T.: Enhanced El Niño-Southern oscillation variability in recent decades, Geophys. Res. Lett., 47, e2019GL083906, https://doi.org/10.1029/2019GL083906, 2019.

Haywood, A. M., Valdes, P. J., and Peck, V. L.: A permanent El Nino-like state during the Pliocene?, Paleoceanography, 22, PA1213, https://doi.org/10.1029/2006PA001323, 2007.

Held, I. M. and Soden, B. J.: Robust responses of the hydrological cycle to global warming, J. Climate, 19, 5686-5699, 2006.

Hoesly, R. M., Smith, S. J., Feng, L., Klimont, Z., JanssensMaenhout, G., Pitkanen, T., Seibert, J. J., Vu, L., Andres, R. J., Bolt, R. M., Bond, T. C., Dawidowski, L., Kholod, N., Kurokawa, J.-I., Li, M., Liu, L., Lu, Z., Moura, M. C. P., O'Rourke, P. R., and Zhang, Q.: Historical (1750-2014) anthropogenic emissions of reactive gases and aerosols from the Community Emissions Data System (CEDS), Geosci. Model Dev., 11, 369-408, https://doi.org/10.5194/gmd-11-369-2018, 2018.

Hu, Z., Kumar, A., Ren, H., Wang, H., L'Heureux, M., and Jin, F.: Weakened interannual variability in the tropical Pacific Ocean since 2000, J. Climate, 26, 2601-2613, 2013.

Hughen, K. A., Schrag, D. P., Jacobsen, S. B., and Hantoro, W.: El Nino during the last interglacial period recorded by a fossil coral from Indonesia, Geophys. Res. Lett., 26, 3129-3132, 1999.

Im, S. H., An, S. I., Kim, S. T., and Jin, F. F.: Feedback processes responsible for El Nino-La Nina amplitude asymmetry, Geophys. Res. Lett., 42, 5556-5563, 2015.

Jansen, E., Fronval, T., Rack, F., and Channell, J. E. T.: PliocenePleistocene ice rafting history and cyclicity in the Nordic Seas during the last 3.5 Myr, Paleoceanography, 15, 709-721, 2000.

Jones, T. R., Roberts, W. H. G., Steig, E. J., Cuffey, K. M., Markle, B. R., and White, J. W. C.: Southern Hemisphere climate variability forced by Northern Hemisphere ice-sheet topography, Nature, 554, 351-355, 2018.

Juckes, M., Taylor, K. E., Durack, P. J., Lawrence, B., Mizielinski, M. S., Pamment, A., Peterschmitt, J.-Y., Rixen, M., and Sénési, S.: The CMIP6 Data Request (DREQ, version 01.00.31), Geosci. Model Dev., 13, 201-224, https://doi.org/10.5194/gmd-13-2012020, 2020.

Kageyama, M., Albani, S., Braconnot, P., Harrison, S. P., Hopcroft, P. O., Ivanovic, R. F., Lambert, F., Marti, O., Peltier, W. R., Peterschmitt, J.-Y., Roche, D. M., Tarasov, L., Zhang, X., Brady, E. C., Haywood, A. M., LeGrande, A. N., Lunt, D. J., Mahowald, N. M., Mikolajewicz, U., Nisancioglu, K. H., Otto-Bliesner, B. L., Renssen, H., Tomas, R. A., Zhang, Q., Abe-Ouchi, A., Bartlein, P. J., Cao, J., Li, Q., Lohmann, G., Ohgaito, R., Shi, X., Volodin, E., Yoshida, K., Zhang, X., and Zheng, W.: The PMIP4 contribution to CMIP6 - Part 4: Scientific objectives and experimental design of the PMIP4-CMIP6 Last Glacial Maximum experiments and PMIP4 sensitivity experiments, Geosci. Model Dev., 10, 4035-4055, https://doi.org/10.5194/gmd-10-4035-2017, 2017.

Kageyama, M., Braconnot, P., Harrison, S. P., Haywood, A. M., Jungclaus, J. H., Otto-Bliesner, B. L., Peterschmitt, J.-Y., AbeOuchi, A., Albani, S., Bartlein, P. J., Brierley, C., Crucifix, M., Dolan, A., Fernandez-Donado, L., Fischer, H., Hopcroft, P. O., Ivanovic, R. F., Lambert, F., Lunt, D. J., Mahowald, N. M., Peltier, W. R., Phipps, S. J., Roche, D. M., Schmidt, G. A., Tarasov, L., Valdes, P. J., Zhang, Q., and Zhou, T.: The PMIP4 contribution to CMIP6 - Part 1: Overview and over- 
arching analysis plan, Geosci. Model Dev., 11, 1033-1057, https://doi.org/10.5194/gmd-11-1033-2018, 2018.

Karamperidou, C., Di Nezio, P. N., Timmermann, A., Jin, F. F., and Cobb, K. M.: The response of ENSO flavors to mid-Holocene climate: Implications for proxy interpretation, Paleoceanography, 30, 527-547, 2015.

Khider, D., Stott, L. D., Emile-Geay, J., Thunell, R., and Hammond, D. E.: Assessing El Nino Southern Oscillation variability during the past millennium, Paleoceanography, 26, PA3222, https://doi.org/10.1029/2011PA002139, 2011.

Kim, S. T. and Jin, F.-F.: An ENSO stability analysis. Part II: results from the twentieth and twenty-first century simulations of the CMIP3 models, Clim. Dynam., 36, 1609-1627, 2011.

Kim, S. T., Cai, W., Jin, F.-F., Yu, J.-Y.: ENSO stability in coupled climate models and its association with mean state, Clim. Dynam., 42, 3313-3321, 2014.

Knutti, R., Masson, D., and Gettelman, A.: Climate model genealogy: Generation CMIP5 and how we got there, Geophys. Res. Lett., 40, 1194-1199, 2013.

Koutavas, A. and Joanides, S.: El Nino-Southern Oscillation extrema in the Holocene and Last Glacial Maximum, Paleoceanography, 27, PA4208, https://doi.org/10.1029/2012PA002378, 2012.

Koutavas, A., Lynch-Stieglitz, J., Marchitto, T. M., and Sachs, J. P.: El Nino-like pattern in ice age tropical Pacific sea surface temperature, Science, 297, 226-230, 2002.

Koutavas, A., Demenocal, P. B., Olive, G. C., and Lynch-Stieglitz, J.: Mid-Holocene El Nino-Southern Oscillation (ENSO) attenuation revealed by individual foraminifera in eastern tropical $\mathrm{Pa}-$ cific sediments, Geology, 34, 993-996, 2006.

Kukla, G. J., Clement, A. C., Cane, M. A., Gavin, J. E., and Zebiak, S. E.: Last interglacial and early glacial ENSO, Quaternary Res., 58, 27-31, 2002.

Latif, M. and Keenlyside, N. S.: El Niño/Southern Oscillation response to global warming, P. Natl. Acad. Sci. USA, 106, 2057820583, 2009.

Leduc, G., Vidal, L., Cartapanis, O., and Baird, E.: Modes of eastern equatorial Pacific thermocline variability: implications for ENSO dynamics over the last glacial period, Paleoceanography, 24, PA3202, https://doi.org/10.1029/2008PA001701, 2009.

Levine, A., Jin, F. F., and McPhaden, M. J.: Extreme Noise-Extreme El Nino: How State-Dependent Noise Forcing Creates El NinoLa Nina Asymmetry, J. Climate, 29, 5483-5499, 2016.

Lewis, S. C. and LeGrande, A. N.: Stability of ENSO and its tropical Pacific teleconnections over the Last Millennium, Clim. Past, 11, 1347-1360, https://doi.org/10.5194/cp-11-1347-2015, 2015.

Lian, T., Chen, D. K., Ying, J., Huang, P., and Tang, Y. M.: Tropical Pacific trends under global warming: El Nino-like or La Ninalike?, Natl. Sci. Rev., 5, 810-812, 2018.

Liu, Z.: A Simple Model Study of ENSO Suppression by External Periodic Forcing, J. Climate, 15, 1088-1098, 2002.

Liu, Z., Kutzbach, J., and Wu, L.: Modeling climate shift of El Nino variability in the Holocene, Geophys. Res. Lett., 27, 2265-2268, 2000.

Liu, Z., Vavrus, S., He, F., Wen, N., and Zhong, Y.: Rethinking Tropical Ocean Response to Global Warming: The Enhanced Equatorial Warming, J. Climate, 18, 4684-4700, 2005.
Liu, Z. Y., Lu, Z. Y., Wen, X. Y., Otto-Bliesner, B. L., Timmermann, A., and Cobb, K. M.: Evolution and forcing mechanisms of El Nino over the past 21,000 years, Nature, 515, 550-553, 2014.

Lloyd, J., Guilyardi, E., and Weller, H.: The role of atmosphere feedbacks during ENSO in the CMIP3 models. Part III: the shortwave flux feedback, J. Climate, 25, 4275-4293, 2012.

Lu, J., Chen, G., and Frierson, D. M. W.: Response of the Zonal Mean Atmospheric Circulation to El Nino versus Global Warming, J. Climate, 21, 5835-5851, 2008.

Lu, Z. Y., Liu, Z. Y., Zhu, J., and Cobb, K. M.: A Review of Paleo El Nino-Southern Oscillation, Atmos.-Basel, 9, 130, https://doi.org/10.3390/atmos9040130, 2018.

Luan, Y., Braconnot, P., Yu, Y., Zheng, W., and Marti, O.: Early and mid-Holocene climate in the tropical Pacific: seasonal cycle and interannual variability induced by insolation changes, Clim. Past, 8, 1093-1108, https://doi.org/10.5194/cp-8-1093-2012, 2012.

Manucharyan, G. E. and Fedorov, A. V.: Robust ENSO across a Wide Range of Climates, J. Climate, 27, 5836-5850, 2014.

MARGO Project Members, Waelbroeck, C., Paul, A., Kucera, M., Rosell-Melé, A., Weinelt, M., Schneider, R., Mix, A., Abelmann, A., and Armand, L.: Constraints on the magnitude and patterns of ocean cooling at the Last Glacial Maximum, Nat. Geosci., 2, 127-132, https://doi.org/10.1038/ngeo411, 2009.

Masson-Delmotte, V., Schulz, M., Abe-Ouchi, A., Beer, J., Ganopolski, A., Rouco, J. F. G., Jansen, E., Lambeck, K., Luterbacher, J., Naish, T., Osborn, T., Otto-Bliesner, B., Quinn, T., Ramesh, R., Rojas, M., Shao, X. M., Timmermann, A., Anchukaitis, K., Arblaster, J., Bartlein, P. J., Benito, G., Clark, P., Comiso, J. C., Crowley, T., De Deckker, P., de Vernal, A., Delmonte, B., DiNezio, P., Dokken, T., Dowsett, H. J., Edwards, R. L., Fischer, H., Fleitmann, D., Foster, G., Frohlich, C., Govin, A., Hall, A., Hargreaves, J., Haywood, A., Hollis, C., Horton, B., Kageyama, M., Knutti, R., Kopp, R., Krinner, G., Landais, A., Li, C., Lunt, D., Mahowald, N., McGregor, S., Meehl, G., Mitrovica, J. X., Moberg, A., Mudelsee, M., Muhs, D. R., Mulitza, S., Muller, S., Overland, J., Parrenin, F., Pearson, P., Robock, A., Rohling, E., Salzmann, U., Savarino, J., Sedlacek, J., Shakun, J., Shindell, D., Smerdon, J., Solomina, O., Tarasov, P., Vinther, B., Waelbroeck, C., Wolf-Gladrow, D., Yokoyama, Y., Yoshimori, M., Zachos, J., and Zwartz, D.: Information from Paleoclimate Archives, Climate Change 2013: The Physical Science Basis, 383-464, 2014.

McGregor, H. V. and Gagan, M. K.: Western Pacific coral delta $\mathrm{O}-18$ records of anomalous Holocene variability in the $\mathrm{El}$ Nino-Southern Oscillation, Geophys. Res. Lett., 31, L11204, https://doi.org/10.1029/2004GL019972, 2004.

McGregor, H. V., Fischer, M. J., Gagan, M. K., Fink, D., Phipps, S. J., Wong, H., and Woodroffe, C. D.: A weak El Niño/Southern Oscillation with delayed seasonal growth around 4300 years ago, Nat. Geosci., 6, 949-953, https://doi.org/10.1038/ngeo1936, 2013.

Meinshausen, M., Vogel, E., Nauels, A., Lorbacher, K., Meinshausen, N., Etheridge, D. M., Fraser, P. J., Montzka, S. A., Rayner, P. J., Trudinger, C. M., Krummel, P. B., Beyerle, U., Canadell, J. G., Daniel, J. S., Enting, I. G., Law, R. M., Lunder, C. R., O’Doherty, S., Prinn, R. G., Reimann, S., Rubino, M., Velders, G. J. M., Vollmer, M. K., Wang, R. H. J., and Weiss, R.: Historical greenhouse gas concentrations for cli- 
mate modelling (CMIP6), Geosci. Model Dev., 10, 2057-2116, https://doi.org/10.5194/gmd-10-2057-2017, 2017.

Merryfield, W. J.: Changes to ENSO under $\mathrm{CO}_{2}$ doubling in a multimodel ensemble, J. Climate, 19, 4009-4027, 2006.

Neelin, J. D., Jin, F. F., and Syu, H. H.: Variations in ENSO phase locking, J. Climate, 13, 2570-2590, 2000.

Nguyen, H., Evans, A., Lucas, C., Smith, I., and Timbal, B.: The Hadley Circulation in Reanalyses: Climatology, Variability, and Change, J. Climate, 26, 3357-3376, 2013.

Okumura, Y. M., Ohba, M., Deser, C., and Ueda, H.: A Proposed Mechanism for the Asymmetric Duration of El Nino and La Nina, J. Climate, 24, 3822-3829, 2011.

Otto-Bliesner, B. L., Schneider, R., Brady, E., Kucera, M., AbeOuchi, A., Bard, E., Braconnot, P., Crucifix, M., Hewitt, C., and Kageyama, M.: A comparison of PMIP2 model simulations and the MARGO proxy reconstruction for tropical sea surface temperatures at last glacial maximum, Clim. Dynam., 32, 799-815, 2009.

Otto-Bliesner, B. L., Rosenbloom, N., Stone, E. J., McKay, N. P., Lunt, D. J., Brady, E. C., and Overpeck, J. T.: How warm was the last interglacial? New model-data comparisons, Philos. T. Roy. Soc. A, 371, 20130097, https://doi.org/10.1098/rsta.2013.0097, 2013.

Otto-Bliesner, B. L., Braconnot, P., Harrison, S. P., Lunt, D. J., Abe-Ouchi, A., Albani, S., Bartlein, P. J., Capron, E., Carlson, A. E., Dutton, A., Fischer, H., Goelzer, H., Govin, A., Haywood, A., Joos, F., LeGrande, A. N., Lipscomb, W. H., Lohmann, G., Mahowald, N., Nehrbass-Ahles, C., Pausata, F. S. R., Peterschmitt, J.-Y., Phipps, S. J., Renssen, H., and Zhang, Q.: The PMIP4 contribution to CMIP6 - Part 2: Two interglacials, scientific objective and experimental design for Holocene and Last Interglacial simulations, Geosci. Model Dev., 10, 3979-4003, https://doi.org/10.5194/gmd-10-3979-2017, 2017.

Otto-Bliesner, B. L., Brady, E. C., Zhao, A., Brierley, C., Axford, Y., Capron, E., Govin, A., Hoffman, J., Isaacs, E., Kageyama, M., Scussolini, P., Tzedakis, P. C., Williams, C., Wolff, E., AbeOuchi, A., Braconnot, P., Ramos Buarque, S., Cao, J., de Vernal, A., Guarino, M. V., Guo, C., LeGrande, A. N., Lohmann, G., Meissner, K., Menviel, L., Nisancioglu, K., O’ishi, R., Salas Y Melia, D., Shi, X., Sicard, M., Sime, L., Tomas, R., Volodin, E., Yeung, N., Zhang, Q., Zhang, Z., and Zheng, W.: Largescale features of Last Interglacial climate: Results from evaluating the lig127k simulations for CMIP6-PMIP4, Clim. Past Discuss., https://doi.org/10.5194/cp-2019-174, in review, 2020.

Pan, A., Liu, Q., and Liu, Z.: Periodic forcing and ENSO suppression in the Cane-Zebiak model, J. oceanogr., 61, 109-113, 2005.

Pausata, F. S., Zhang, Q., Muschitiello, F., Lu, Z., Chafik, L., Niedermeyer, E. M., Stager, J. C., Cobb, K. M., and Liu, Z.: Greening of the Sahara suppressed ENSO activity during the mid-Holocene, Nat. Commun., 8, 16020, https://doi.org/10.1038/ncomms16020, 2017.

Phillips, A. S., Deser, C., and Fasullo, J.: Evaluating Modes of Variability in Climate Models, Eos, Trans. Am. Geophys. Union, 95, 453-455, 2014.

Power, S. B. and Delage, F. P.: El Niño-southern oscillation and associated climatic conditions around the world during the latter half of the twenty-first century, J. Climate, 31, 6189-6207, 2018.
Power, S., Delage, F., Chung, C., Kociuba, G., and Keay, K.: Robust twenty-first-century projections of El Nino and related precipitation variability, Nature, 502, 541-545, 2013.

Ramanathan, V. and Collins, W.: Thermodynamic Regulation of Ocean Warming by Cirrus Clouds Deduced from Observations of the 1987 El-Nino, Nature, 351, 27-32, 1991.

Ravelo, A. C., Dekens, P. S., and McCarthy, M.: Evidence for El Niño-like conditions during the Pliocene, GSA Today, 16, 4-11, 2006.

Rayner, N. A., Parker, D. E., Horton, E. B., Folland, C. K., Alexander, L. V., Rowell, D. P., Kent, E. C., and Kaplan, A.: Global analyses of sea surface temperature, sea ice, and night marine air temperature since the late nineteenth century, J. Geophys. Res.-Atmos., 108, 4407, https://doi.org/10.1029/2002JD002670, 2003.

Rein, B., Luckge, A., Reinhardt, L., Sirocko, F., Wolf, A., and Dullo, W. C.: El Nino variability off Peru during the last 20,000 years, Paleoceanography, 20, PA4003, https://doi.org/10.1029/2004PA001099, 2005.

Riedinger, M. A., Steinitz-Kannan, M., Last, W. M., and Brenner, M.: A similar to $6100 \mathrm{C}-14 \mathrm{yr}$ record of El Nino activity from the Galapagos Islands, J. Paleolimnol., 27, 1-7, 2002.

Roberts, W. H., Battisti, D. S., and Tudhope, A. W.: ENSO in the Mid-Holocene according to CSM and HadCM3, J. Climate, 27, 1223-1242, 2014.

Rustic, G. R., Koutavas, A., Marchitto, T. M., and Linsley, B. K.: Dynamical excitation of the tropical Pacific Ocean and ENSO variability by Little Ice Age cooling, Science, 350, 1537-1541, 2015.

Sadekov, A. Y., Ganeshram, R., Pichevin, L., Berdin, R., McClymont, E., Elderfield, H., and Tudhope, A. W.: Palaeoclimate reconstructions reveal a strong link between El Nino-Southern Oscillation and Tropical Pacific mean state, Nat. Commun., 4, 2692, https://doi.org/10.1038/ncomms3692, 2013.

Saint-Lu, M., Braconnot, P., Leloup, J., Lengaigne, M., and Marti, O.: Changes in the ENSO/SPCZ relationship from past to future climates, Earth Planet. Sci. Lett., 412, 18-24, 2015.

Salau, O., Schneider, B., Park, W., Khon, V., and Latif, M.: Modeling the ENSO impact of orbitally induced mean state climate changes, J. Geophys. Res.-Oceans, 117, C05043, https://doi.org/10.1029/2011JC007742, 2012.

Scroxton, N., Bonham, S. G., Rickaby, R. E. M., Lawrence, S. H. F., Hermoso, M., and Haywood, A. M.: Persistent El Nino-Southern Oscillation variation during the Pliocene Epoch, Paleoceanography, 26, PA2215, https://doi.org/10.1029/2010PA002097, 2011.

Scussolini, P., Bakker, P., Guo, C. C., Stepanek, C., Zhang, Q., Braconnot, P., Cao, J., Guarino, M. V., Coumou, D., Prange, M., Ward, P. J., Renssen, H., Kageyama, M., Otto-Bliesner, B., and Aerts, J. C. J. H.: Agreement between reconstructed and modeled boreal precipitation of the Last Interglacial, Sci. Adv., 5, eaax7047, https://doi.org/10.1126/sciadv.aax7047, 2019.

Seager, R., Cane, M., Henderson, N., Lee, D. E., Abernathey, R., and Zhang, H. H.: Strengthening tropical Pacific zonal sea surface temperature gradient consistent with rising greenhouse gases, Nat. Clim. Change, 9, 517-522, 2019.

Shin, S.-I., Sardeshmukh, P. D., Webb, R. S., Oglesby, R. J., and Barsugli, J. J.: Understanding the Mid-Holocene Climate, J. Climate, 19, 2801-2817, 2006. 
Stein, K., Timmermann, A., and Schneider, N.: Phase Synchronization of the El Nino-Southern Oscillation with the Annual Cycle, Phys. Rev. Lett., 107, 128501, 2011.

Stevenson, S. L.: Significant changes to ENSO strength and impacts in the twenty-first century: Results from CMIP5, Geophys. Res. Lett., 39, L17703, https://doi.org/10.1029/2012GL052759, 2012.

Stouffer, R. J., Weaver, A. J., and Eby, M.: A method for obtaining pre-twentieth century initial conditions for use in climate change studies, Clim. Dynam., 23, 327-339, 2004.

Stuecker, M. F., Jin, F. F., and Timmermann, A.: El Nino-Southern Oscillation frequency cascade, P. Natl. Acad. Sci. USA, 112, 13490-13495, 2015.

Tang, Y. and Yu, B.: MJO and its relationship to ENSO, J. Geophys. Res.-Atmos., 113, D14106, https://doi.org/10.1029/2007JD009230, 2008.

Taschetto, A. S., Gupta, A. S., Jourdain, N. C., Santoso, A., Ummenhofer, C. C., and England, M. H.: Cold tongue and warm pool ENSO events in CMIP5: mean state and future projections, J. Climate, 27, 2861-2885, 2014.

Taylor, K. E., Stouffer, R. J., and Meehl, G. A.: An Overview of CMIP5 and the Experiment Design, B. Am. Meteorol. Soc., 93, 485-498, 2012.

Tian, B. and Dong, X.:The double-ITCZ Bias in CMIP3, CMIP5 and CMIP 6 models based on annual mean precipitation, Geophys. Res. Lett., 47, e2020GL087232, https://doi.org/10.1029/2020GL087232, 2020.

Tian, Z., Li, T., Jiang, D., and Chen, L.: Causes of ENSO weakening during the Mid-Holocene, J. Climate, 30, 7049-7070, 2017.

Timmermann, A., Oberhuber, J., Bacher, A., Esch, M., Latif, M., and Roeckner, E.: Increased El Nino frequency in a climate model forced by future greenhouse warming, Nature, 398, 694697, 1999.

Timmermann, A., Okumura, Y., An, S. I., Clement, A., Dong, B., Guilyardi, E., Hu, A., Jungclaus, J. H., Renold, M., Stocker, T. F., Stouffer, R. J., Sutton, R., Xie, S. P., and Yin, J.: The influence of a weakening of the Atlantic meridional overturning circulation on ENSO, J. Climate, 20, 4899-4919, 2007.

Timmermann, A., An, S.-I., Kug, J.-S., Jin, F.-F., Cai, W., Capotondi, A., Cobb, K. M., Lengaigne, M., McPhaden, M. J., Stuecker, M. F., Stein, K., Wittenberg, A. T., Yun, K.-S., Bayr, T., Chen, H.-C., Chikamoto, Y., Dewitte, B., Dommenget, D., Grothe, P., Guilyardi, E., Ham, Y.-G., Hayashi, M., Ineson, S., Kang, D., Kim, S., Kim, W., Lee, J.-Y., Li, T., Luo, J.-J., McGregor, S., Planton, Y., Power, S., Rashid, H., Ren, H.-L., Santoso, A., Takahashi, K., Todd, A., Wang, G., Wang, G., Xie, R., Yang, W.-H., Yeh, S.-W., Yoon, J., Zeller, E., and Zhang, X.: El NiñoSouthern Oscillation complexity, Nature, 559, 535-545, 2018.

Trenberth, K. E.: The definition of El Nino, B. Am. Meteorol. Soc., 78, 2771-2777, 1997.

Trenberth, K. E. and Hoar, T. J.: El Nino and climate change, Geophys. Res. Lett., 24, 3057-3060, 1997.

Tudhope, A. W., Chilcott, C. P., McCulloch, M. T., Cook, E. R., Chappell, J., Ellam, R. M., Lea, D. W., Lough, J. M., and Shimmield, G. B.: Variability in the El Nino - Southern oscillation through a glacial-interglacial cycle, Science, 291, 1511-1517, 2001.

van Marle, M. J. E., Kloster, S., Magi, B. I., Marlon, J. R., Daniau, A.-L., Field, R. D., Arneth, A., Forrest, M., Hantson, S., Kehrwald, N. M., Knorr, W., Lasslop, G., Li, F., Man- geon, S., Yue, C., Kaiser, J. W., and van der Werf, G. R.: Historic global biomass burning emissions for CMIP6 (BB4CMIP) based on merging satellite observations with proxies and fire models (1750-2015), Geosci. Model Dev., 10, 3329-3357, https://doi.org/10.5194/gmd-10-3329-2017, 2017.

Vecchi, G. A. and Soden, B. J.: Global warming and the weakening of the tropical circulation, J. Climate, 20, 4316-4340, 2007.

Wang, G. J., Cai, W. J., Gan, B. L., Wu, L. X., Santoso, A., Lin, X. P., Chen, Z. H., and McPhaden, M. J.: Continued increase of extreme El Nino frequency long after 1.5 degrees $\mathrm{C}$ warming stabilization, Nat. Clim. Change, 7, 568-572, 2017.

Wara, M. W., Ravelo, A. C., and Delaney, M. L.: Permanent El Niño-like conditions during the Pliocene warm period, Science, 309, 758-761, 2005.

Watanabe, T., Suzuki, A., Minobe, S., Kawashima, T., Kameo, K., Minoshima, K., Aguilar, Y. M., Wani, R., Kawahata, H., Sowa, K., Nagai, T., and Kase, T.: Permanent El Nino during the Pliocene warm period not supported by coral evidence, Nature, 471, 209-211, 2011.

White, S. M. and Ravelo, A. C.: Dampened El Niño in the early Pliocene warm period, Geophys. Res. Lett., 47, e2019GL085504, https://doi.org/10.1029/2019GL085504, 2020.

White, S. M., Ravelo, A. C., and Polissar, P. J.: Dampened El Niño in the early and mid-Holocene due to insolation-forced warming/deepening of the thermocline, Geophys. Res. Lett., 45, 316326, 2018.

Widlansky, M. J., Timmermann, A., Stein, K., McGregor, S., Schneider, N., England, M. H., Lengaigne, M., and Cai, W. J.: Changes in South Pacific rainfall bands in a warming climate, Nat. Clim. Change, 3, 417-423, 2013.

Wittenberg, A. T.: Are historical records sufficient to constrain ENSO simulations?, Geophys. Res. Lett., 36, L12702, https://doi.org/10.1029/2009GL038710, 2009.

Xie, S.-P., Deser, C., Vecchi, G. A., Ma, J., Teng, H., and Wittenberg, A. T.: Global warming pattern formation: Sea surface temperature and rainfall, J. Climate, 23, 966-986, 2010.

Yang, S., Li, Z., Yu, J.-Y., Hu, X., Dong, W., and He, S.: El NiñoSouthern oscillation and its impact in the changing climate, Natl. Sci. Rev., 5, 840-857, 2018.

Yeh, S. W. and Kirtman, B. P.: ENSO amplitude changes due to climate change projections in different coupled models, J. Climate, 20, 203-217, 2007.

Yeh, S. W., Kug, J. S., Dewitte, B., Kwon, M. H., Kirtman, B. P., and Jin, F. F.: El Nino in a changing climate, Nature, 461, 511-U570, 2009.

Yeh, S.-W., Kug, J.-S., and An, S.-I.: Recent progress on two types of El Niño: Observations, dynamics, and future changes, AsiaPac. J. Atmos. Sci., 50, 69-81, 2014.

Yeh, S. W., Cai, W. J., Min, S. K., McPhaden, M. J., Dommenget, D., Dewitte, B., Collins, M., Ashok, K., An, S. I., Yim, B. Y., and Kug, J. S.: ENSO Atmospheric Teleconnections and Their Response to Greenhouse Gas Forcing, Rev. Geophys., 56, 185206, 2018.

Zebiak, S. E.: Air-sea interaction in the equatorial Atlantic region, J. Climate, 6, 1567-1586, 1993.

Zhang, C. D. and Gottschalck, J.: SST anomalies of ENSO and the Madden-Julian oscillation in the equatorial Pacific, J. Climate, 15, 2429-2445, 2002. 
Zhang, Q., Guan, Y., and Yang, H. J.: ENSO amplitude change in observation and coupled models, Adv. Atmos. Sci., 25, 361-366, 2008.

Zhang, T. and Sun, D. Z.: ENSO Asymmetry in CMIP5 Models, J. Climate, 27, 4070-4093, 2014.

Zhang, X. X., Liu, H. L., and Zhang, M. H.: Double ITCZ in Coupled Ocean-Atmosphere Models: From CMIP3 to CMIP5, Geophys. Res. Lett., 42, 8651-8659, 2015.
Zheng, W., Braconnot, P., Guilyardi, E., Merkel, U., and Yu, Y.: ENSO at $6 \mathrm{ka}$ and $21 \mathrm{ka}$ from ocean-atmosphere coupled model simulations, Clim. Dynam., 30, 745-762, 2008.

Zhu, J., Liu, Z., Brady,E., Otto-Bliesner, B., Zhang, J., Noone, D., Tomas, R., Nusbaumer, J., Wong, T., Jahn, A., and Tabor, C.: Reduced ENSO variability at the LGM revealed by an isotopeenabled earth system model, Geophys. Res. Lett., 44, 69846992, 2017. 